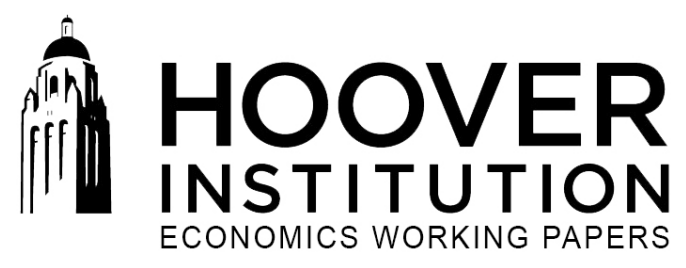

\title{
Human Capital Quality and Aggregate Income Differences: Development Accounting For U.S. States
}

Eric A. Hanushek, Jens Ruhose, and Ludger Woessmann

Economics Working Paper 15112

\author{
HOOVER INSTITUTION \\ 434 GALVEZ MALL \\ STANFORD UNIVERSITY \\ STANFORD, CA 94305-6010
}

June 2015

\begin{abstract}
Although many U.S. state policies presume that human capital is important for state economic development, there is little research linking better education to state incomes. In a complement to international studies of income differences, we investigate the extent to which quality-adjusted measures of human capital can explain within-country income differences. We develop detailed measures of state human capital based on school attainment from census micro data and on cognitive skills from state- and country-of-origin achievement tests. Partitioning current state workforces into state locals, interstate migrants, and immigrants, we adjust achievement scores for selective migration. We use the new human capital measures in development accounting analyses calibrated with standard production parameters. We find that differences in human capital account for 20-35 percent of the current variation in per-capita GDP among states, with roughly even contributions by school attainment and cognitive skills. Similar results emerge from growth accounting analyses.
\end{abstract}

The Hoover Institution Economics Working Paper Series allows authors to distribute research for discussion and comment among other researchers. Working papers reflect the views of the authors and not the views of the Hoover Institution. 
Human Capital Quality and Aggregate Income Differences: Development Accounting

For U.S. States

Eric A. Hanushek, Jens Ruhose, and Ludger Woessmann

Economics Working Paper 15112

June 2015

JEL No. I25, J24, O47

\section{Abstract:}

Although many U.S. state policies presume that human capital is important for state economic development, there is little research linking better education to state incomes. In a complement to international studies of income differences, we investigate the extent to which quality-adjusted measures of human capital can explain within-country income differences. We develop detailed measures of state human capital based on school attainment from census micro data and on cognitive skills from state- and country-of-origin achievement tests. Partitioning current state workforces into state locals, interstate migrants, and immigrants, we adjust achievement scores for selective migration. We use the new human capital measures in development accounting analyses calibrated with standard production parameters. We find that differences in human capital account for 20-35 percent of the current variation in per-capita GDP among states, with roughly even contributions by school attainment and cognitive skills. Similar results emerge from growth accounting analyses.

Eric A. Hanushek

Hoover Institution

Stanford University

Stanford, CA 94305-6010

and NBER

hanushek@stanford.edu
Ludger Woessmann

University of Munich

Ifo Institute for Economic Research and CESifo

Poschingerstr. 5

81679 Munich, Germany

woessmann@ifo.de

Jens Ruhose

University of Munich

Ifo Institute for Economic Research and CESifo

Poeschingerstr. 5

81679 Munich, Germany

ruhose@ifo.de

Acknowledgements:

We gratefully acknowledge comments from Jeff Smith and Chad Jones, as well as seminar participants at Harvard, UCLA, Koç, the AEA meetings, and the CESifo area conference on economics of education. This research was supported by the Kern Family Foundation. The views expressed herein are those of the authors and do not necessarily reflect the views of the National Bureau of Economic Research.

(C) 2015 by Eric A. Hanushek, Jens Ruhose, and Ludger Woessmann. All rights reserved. Short sections of text, not to exceed two paragraphs, may be quoted without explicit permission provided that full credit, including (C) notice, is given to the source. 


\section{Introduction}

A key element of economic development policies in the United States and elsewhere has been the improvement of human capital through such policies as upgrading public schooling or enticing the migration of skilled workers. Empirical research has paid considerable attention to the role of human capital in determining international differences in income and growth, where results suggest that 20-40 percent of existing cross-country income differences can be accounted for by differences in human capital incorporating both quantity and quality of education (e.g., Schoellman (2012); Hanushek and Woessmann (2012b)). However, free movement of workers, capital, and technologies, among others, and the resulting smaller income differences within a country make it unclear to what extent international findings derived from income differences of a factor of 30, such as between the United States and Uganda, can inform human capital policies of U.S. states. Relatedly, a concern with available cross-country analysis is the ability to develop consistent economic models across extremely diverse economies. It is much more plausible that U.S. states operate under a common aggregate production function. Further, the common cultural and institutional milieu across the U.S. eliminates major structural factors that are generally unmeasured and as such likely to distort cross-country analyses. Issues of data quality across diverse countries add to these concerns. This paper develops detailed measures of the human capital of U.S. states based on both school attainment and cognitive skills in order to consider directly the sources of economic differences across U.S. states.

Not much attention has been paid to the substantial income differences among U.S. states and the role of differences in state human capital as a possible source. The magnitude of variation in Gross Domestic Product (GDP) per capita across U.S. states is actually quite significant (albeit obviously significantly less than cross-country variations). At \$59,251, percapita GDP in Connecticut is twice as high as that in West Virginia. ${ }^{1}$ The standard deviation in state incomes of $\$ 6,388$ is more than 15 percent of the national average, indicating that states have clearly reached very different levels of development. In addition, average annual growth rates between 1970 and 2007 range from 1.6 percent in Michigan to 2.9 percent in South Dakota. That is, while South Dakota's GDP per capita increased by 187 percent - lifting it from $43^{\text {rd }}$ to

\footnotetext{
${ }^{1}$ See Appendix Tables A1 and A2. Data refer to 2007 in 2005 U.S. dollars. Throughout the paper, the analysis stops in 2007 to avoid any distortion of the long-run picture by the 2008 financial crisis, but results are very similar for 2010. In addition, Alaska, Delaware, and Wyoming are excluded from the analysis because of their GDP's dependence on natural resources or finance.
} 
$21^{\text {st }}$ in the national state ranking - Michigan's GDP per capita increased by 77 percent - making it drop from $9^{\text {th }}$ to $35^{\text {th }}$ rank. As is evident from Figure 1, which shows the full distribution of state GDPs per capita from 1970 to 2007, the variation (in terms of standard deviations) in state incomes has more than doubled since 1970.

A key component of our addressing the underlying causes of these variations is developing several alternate estimates of the human capital of workers in each U.S. state. We consider two dimensions of human capital - a quantity and a quality dimension. Measures of years of schooling of each state can readily be derived from Census micro data. The more challenging task is to derive measures of the cognitive skills of each state's working-age population. Crossstate and cross-country migration can lead to substantial differences between schooling location and current residency (Bound et al. (2004)), so that test scores of current students do not accurately indicate the skills of current workers. However, because we have the migration history of current workers - including international migrants - we can construct a state by stateplus-country matrix that maps the current residence of the workforce of each state to the appropriate states of schooling. Using measures of achievement test scores by schooling location from the National Assessment of Educational Progress (NAEP) and international tests along with this migration matrix allows us to construct measures of the cognitive skills of the working-age population of each state. Testing, however, was not done during the schooling years of some older workers, so we also develop two methods to project backward state NAEP test scores which are available since 1990 - in order to allow for variation in cognitive skills over age cohorts.

We pay particular attention to selective migration. As indicated in the discussions of the effects of state variation in school quality on individual returns to education (Card and Krueger (1992)), selectivity of cross-state migration is an important issue (Heckman, Layne-Farrar, and Todd (1996)). ${ }^{2}$ We adjust the skill measures for the selectivity of interstate migrants based on separate test scores by educational background of parents. In addition, we adjust for the selectivity of international immigrants based on their home-country test score distributions using the $90^{\text {th }}$ percentile in our preferred specification - in order to account for the highly selective nature of international migration (e.g., Borjas (1987); Grogger and Hanson (2011)).

\footnotetext{
${ }^{2}$ See Borjas, Bronars, and Trejo (1992) and Dahl (2002) for additional evidence of selective regional migration within the United States.
} 
Altogether, our most refined test score measure is based on more than a thousand different subpopulation cells (of different age cohorts from different states and countries of origin with different educational backgrounds) for each state and year.

The two dimensions of a state's human capital stock are integrated according to market prices in a Mincer-type specification of aggregate human capital. The parameters of the economic value of school attainment and cognitive skills are derived from the micro literature. These new measures of state human capital are central to our analysis of state income differences.

To avoid identification problems of estimating parameters in aggregate regression analyses, we employ a standard development accounting approach that uses an aggregate Cobb-Douglas production function to decompose output variation into contributions by factor inputs. Depending on the specific test score measure and accounting method used, we find that state differences in human capital account for about 20-35 percent of the current variation in GDP per capita across U.S. states. Differences in school attainment and in cognitive skills contribute roughly evenly to this, implying that the evidence across U.S. states is surprisingly similar to the existing cross-country evidence. We also introduce our human capital measures into growth accounting analyses, where they account for roughly similar shares of average U.S. growth since 1970, with some variation across states.

We view these estimates as lower bounds on the impact of human capital. They are derived from a neoclassical production function that describes growth as occurring through the added accumulation of human capital. ${ }^{3}$ This formulation ignores any elements of endogenous growth or complementarity of inputs and technology. Further, measurement error in human capital likely acts to lessen its role in explaining income differences.

Our analysis contributes a within-country perspective on the substantial literature on human capital in cross-country development accounting analyses. ${ }^{4}$ While much of the literature has focused on years of schooling, an extension to considering differences in the quality of education

\footnotetext{
${ }^{3}$ Growth theory has modeled human capital as an accumulated factor of production in augmented neoclassical growth models (e.g., Mankiw, Romer, and Weil (1992)), as a source of technological change in endogenous growth models (e.g., Lucas (1988); Romer (1990); Aghion and Howitt (1998)), or as a factor crucial for technology adoption in models of knowledge diffusion (e.g., Nelson and Phelps (1966)). While we do not attempt to distinguish among these alternatives here, it is clear that the neoclassical model incorporates a more limited role for human capital than the others.

${ }^{4}$ E.g., Klenow and Rodriquez-Clare (1997); Hall and Jones (1999); Bils and Klenow (2000); Caselli (2005, 2014); and Hsieh and Klenow (2010).
} 
has proved important. Schoellman (2012) estimates quality differences from returns to schooling of immigrants on the U.S. labor market (see also Hendricks (2002)), while Hanushek and Woessmann (2012b) use direct measures of quality differences from test scores. ${ }^{5}$

The role of human capital in cross-state income differences has been much less studied, especially when measurement is expanded from just school attainment to include a quality dimension. Work on convergence across U.S. states has usually not incorporated human capital (e.g., Barro and Sala-i-Martin (1992); Evans and Karras (2006)). Aghion et al. (2009) use crossstate variation to estimate the causal impact of different types of education spending on growth. Turner et al. (2007) and Turner, Tamura, and Mulholland (2013) apply an extensive state-level dataset focused entirely on years of schooling in growth regression and growth accounting analyses of U.S. states over 1840-2000. ${ }^{6}$ The extended analysis in Gennaioli et al. (2013) of regional development for more than 1,500 regions in 110 countries also focuses on years of schooling. In this paper, we aim to understand to what extent differences in human capital can account for the substantial differences in income levels that exist across U.S. states, widening the focus from educational attainment to measures of cognitive skills. ${ }^{7}$

Section 2 describes our construction of state human capital measures from years of schooling and cognitive skills in a Mincer-type specification of aggregate human capital (with further detail provided in the appendix). Section 3 introduces the income data and development accounting framework. Section 4 applies our state human capital measures in development accounting analyses. Section 5 derives how they can be incorporated in growth accounting analyses. Section 6 concludes.

\footnotetext{
${ }^{5}$ See also Gundlach, Rudman, and Woessmann (2002) and Kaarsen (2014). While issues of identification are larger in cross-country growth regressions, their results show a similar pattern on the quantity and quality dimension (see, e.g., Barro (1991) and Mankiw, Romer, and Weil (1992) on school attainment and Hanushek and Kimko (2000), Hanushek and Woessmann (2008, 2012a), and Ciccone and Papaioannou (2009) on cognitive skills).

${ }^{6}$ Examples of analyses of U.S. regional growth and income at the sub-state (city, county, or commuting zone) level include Rappaport and Sachs (2003), Glaeser and Saiz (2004), Higgins, Levy, and Young (2006), Autor, Dorn, and Hanson (2013), and Glaeser, Ponzetto, and Tobio (2014).

${ }^{7}$ Recent contributions to the cross-country literature have generalized the accounting framework to reevaluate the possible role of human capital (Erosa, Koreshkova, and Restuccia (2010); Manuelli and Seshadri (2014); Jones (2014)). In order to highlight the measurement issues of quality and skill differences, here we stick with a standard accounting framework to allow direct comparison with the existing literature in a simple model framework.
} 


\section{Constructing Measures of State Human Capital}

We expand on prior measures of state human capital by bringing in a quality dimension in addition to the more usual quantity dimension. We rely on market prices derived from Mincertype specifications of earnings determination to aggregate years of schooling and cognitive skills into a composite measure of human capital (section 2.1). ${ }^{8}$ Average years of schooling of the labor force in U.S. states can be calculated from Census micro data in a relatively straightforward manner (section 2.2). Obtaining reliable and valid measures of state cognitive skills, however, is a much more substantial task and constitutes a core part of our analysis (section 2.3).

\subsection{A Mincer-Type Measure of Aggregate Human Capital}

Following the existing literature, an obvious starting point for measuring human capital is the quantitative dimension captured by school attainment. Here, however, we explore augmenting school attainment by test scores that are designed to measure cognitive skills. Using the Mincer representation of an earnings function, we create a measure of aggregate human capital per worker $h$ by combining average years of schooling $S$ and test scores $T$ according to prices on the labor market:

$$
h=e^{r S+w T}
$$

The respective parameters $r$ and $w$ are the earnings gradients for each component of human capital and are used as weights to map schooling and test scores into a single human capital indicator according to their respective impact on individual earnings and productivity.

In order to calibrate the human capital measure empirically, we take existing estimates from the micro literature. In the United States, the gradient for years of schooling is typically estimated to be around $r=0.10$ (e.g., Card (1999)). Thus, an increase in schooling by one year is associated with an increase in earnings by 10 percent.

Estimates of the gradient for cognitive skills $w$ are less commonly available and are not completely satisfactory for our purposes. Several U.S. studies, employing very different datasets and approaches, provide gradient estimates. The first group of studies provides estimates of

\footnotetext{
${ }^{8}$ See Jones (2014) for a general discussion of aggregating human capital in a development accounting context, although that work is more focused on aggregating school attainment in the more challenging cross-country setting.
} 
returns to skills early in a person's career, based on different nationally representative datasets that follow students after they leave school and enter the labor force (Mulligan (1999); Murnane et al. (2000); Lazear (2003)). When scores are standardized, they indicate that one standard deviation increase in mathematics performance at the end of high school translates into 10-15 percent higher annual earnings. ${ }^{9}$ Chetty et al. (2011) look at how kindergarten test scores affect earnings at age 25-27 and find an increase of 18 percent per standard deviation.

However, all of these estimates come early in the workers' career, and there are reasons to expect that these are lower than later in the lifecycle. A rising pattern over the lifecycle could reflect better employer information with experience (Altonji and Pierret (2001)), improved job matches over the career (Jovanovic (1979)), steeper earnings trajectories of people with higher lifetime earnings (Haider and Solon (2006)), or the effects of technological change over time. ${ }^{10}$ Hanushek and Zhang (2009) estimate a gradient of 0.20 for the United States using the International Adult Literacy Survey (IALS), a dataset covering the entire working life. Hanushek et al. (2015) explicitly look at the age pattern of returns and find that the impact of skills indeed rises during the early career. Their estimates for the United States, based on data from the Programme for the International Assessment of Adult Competencies (PIAAC), range between 0.14 and 0.28 depending on the precise specification. ${ }^{11}$

From this range of estimates, we rely in the main analysis on an estimate of returns to prime age workers of 0.20 , or 20 percent higher earnings for one standard deviation of tests. Thus, we calibrate our baseline model with $r=0.1$ and $w=0.2$, which follows from the model in Hanushek and Zhang (2009) that jointly estimates the two gradients in one equation. In robustness checks, we investigate the sensitivity of the estimates to these parameter choices.

\footnotetext{
${ }^{9}$ It is convenient to convert test scores into measures of the distribution of achievement across the population. Examples of earlier studies include Bishop (1989), Murnane, Willett, and Levy (1995), and Neal and Johnson (1996). A separate review of earlier studies of the normalized impact of measured cognitive skills on earnings by Bowles, Gintis, and Osborne (2001) finds that the mean estimate is only 0.07, or slightly over half of the specific studies here. More details on the individual studies shown here can be found in Hanushek (2011).

${ }^{10}$ These estimates are derived from observations at a point in time. Over the past few decades, the returns to skill have risen. If these trends continue, the estimates may understate the lifetime value of skills to individuals. On the other hand, the trends themselves could change in the opposite direction. For an indication of the competing forces over a long period, see Goldin and Katz (2008).

${ }^{11}$ Using yet another method that relies on international test scores and immigrants into the U.S., Hanushek and Woessmann (2012a) obtain an estimate of 14 percent per standard deviation. These estimates come from a difference-in-differences formulation based on whether the immigrant was educated in the home country or in the U.S. They find that skills measured by international math and science tests from each immigrant's home country are significant in explaining earnings within the U.S. While covering the full age range of the workforce, the lower estimates are consistent with the lower gradients for immigrants found in Hanushek et al. (2015).
} 


\subsection{Years of Schooling}

The most straightforward component of state human capital is average completed years of schooling. The U.S. Census micro data permit a calculation of school attainment for the working-age population of each state (Ruggles et al. (2010)). We focus on the population aged 20 to 65 not currently in school.

The transformation of educational degrees into years of schooling follows Jaeger (1997). Due to their relatively weak labor-market performance (Heckman, Humphries, and Mader (2011)), GED holders are assigned 10 years of schooling.

Based on these data, we calculate the average years of schooling completed by the individuals living in a state in the different Census years. ${ }^{12}$ Figure 2 shows the distribution of average years of schooling of U.S. states over time. Mean educational attainment of the workingage population of the median U.S. state has steadily increased, albeit at a decreasing rate, from just over 11 years in 1970 to just over 13 years in 2007. The considerable variation in the average years of schooling across states has noticeably narrowed over time due to migration, school policies, and individual schooling decisions.

\subsection{Cognitive Skills}

The second task is developing a measure of the cognitive skills for each state's working-age population. No complete measure exists for the current working-age population, which is made up of people educated in the state at various times, of people educated in other U.S. states at various times, and of people educated in other countries at various times. In recent periods, statespecific achievement test information is available for current students, and we develop a mapping from these test data to the skills of the current working-age population.

Going from the available information to an estimate of the skills of the state working-age population involves four steps. First, we construct mean test scores of the students of each state across the available test years (section 2.3.1). Second, we adjust state test scores for migration between states, with a special focus on selectivity of the interstate migration flows (section 2.3.2). Third, we adjust the score for international migration, again with a focus on selectivity

${ }^{12}$ Appendix A provides additional detail. Column 2 of Appendix Table A2 reports the average years of completed schooling of the working-age population of each state in 2007. 
(section 2.3.3). Fourth, we allow the state scores to vary over time by projecting available score information backward for older cohorts (section 2.3.4).

Here we just describe the main ideas of the derivations; Appendix B provides additional detail on each of the steps.

\subsubsection{Construction of Mean State Test Scores}

We start by combining all available state test score information into a single average score for each state, using the reliable U.S. state-level test score data from the National Assessment of Educational Progress (NAEP; see National Center for Education Statistics (2014)). In our main analysis, we focus on the NAEP mathematics test scores in grade eight. ${ }^{13}$ For 41 states, NAEP started to collect eighth-grade math test scores on a representative scale at the state level in 1990 and repeated testing every two to four years. From 2003 forward, these test scores are consistently available for all states. An eighth-grader in 1990 would be aged 31 in 2007, implying that the majority of workers in the labor force would not have participated in the testing program.

Importantly, the NAEP state-level test results are quite stable over time. An analysis of the variance of grade eight math tests shows that 88 percent of test variation lies between states and just 12 percent represents variation in state-average scores over the two decades of observations. Thus, we begin by calculating an average state score using all the available NAEP observations for each state, but will subsequently also project age-varying test scores. As described in Appendix B.1, the average state scores are estimated as state fixed effects in a regression with year (and, where applicable, grade-by-subject) fixed effects on scores that were normalized to a common scale that has a U.S. mean of 500 and a U.S. standard deviation of 100 in the year 2011. The average score of each state in eighth-grade math is provided in column 3 of Appendix Table A2.

\footnotetext{
${ }^{13}$ In robustness analyses, we also report results using reading test scores in grade eight, but those are available only from 1998 onwards and additionally have fewer international tests with less complete country coverage. Results are very similar. NAEP also tests students in grade four but these are not available by parental education, which is vital information for our adjustment for selective migration. We did construct mean state test scores for the different grades and subjects, however, and they turn out to be very highly correlated. The correlations range from 0.87 between $8^{\text {th }}$-grade math and $4^{\text {th }}$-grade reading to 0.96 between $8^{\text {th }}$-grade reading and $4^{\text {th }}$-grade reading, indicating that the test scores provide similar information about the position of the state in terms of student achievement.
} 
Our primary analysis relies on these estimates of skills for students educated in each of the states. Ranking states by their average test score, Minnesota, North Dakota, Massachusetts, Montana, and Vermont make up the top five states, whereas Hawaii, New Mexico, Louisiana, Alabama, and Mississippi constitute the bottom five states. The top-performing state (Minnesota) surpasses the bottom-performing state (Mississippi) by 0.87 standard deviations. Various analyses suggest that the average learning gain from one grade to the next is roughly between one-quarter and one-third of a standard deviation in test scores. That is, in eighth-grade math, the average achievement difference between the top- and the bottom-performing state amounts to about three grade-level equivalents.

\subsubsection{Adjustment for Interstate Migration}

The second step of our derivation involves adjusting for migration between U.S. states, first without and then with consideration of selectivity in the migration process.

\section{Adjusting for State of Birth}

Obviously, not all current workers in a state were educated in that state. From the Census data, we know the state of birth of all persons in each state who were born in the United States. On average, somewhat less than 60 percent of the working-age population in 2007 is living in their state of birth (see Figure 3), indicating that many were unlikely to have been educated in their current state of residence. But there is also substantial variation across states. For example, in Nevada, only 16 percent of the state’s residents in 2007 report having been born there. At the other extreme, 78 percent of the population in Louisiana was born there. These numbers indicate that interstate migration is a major issue when assessing the cognitive skills of the working-age population of a state.

To adjust for interstate migration, we start by computing the birthplace composition of each state from the Census data. That is, for each state, we break the state working-age population into state locals (those born in their current state of residence), interstate migrants from all other states (those born in the U.S. but outside current state of residence), and international immigrants (those born outside the U.S.). For the U.S.-born population, we construct a state-by-state matrix of the share of each state's current population born in each of the other states. 
Assuming that interstate migrants have not left their state of birth before finishing grade eight, ${ }^{14}$ we can then combine test scores for the U.S.-born population of a state according to the separate birth-state scores. Our baseline skill measure thus assigns all state locals and all interstate migrants the mean test score of students in their state of birth - which only for the state locals will be equivalent to the mean test score of their state of residence. This baseline skill measure is reported in column 4 of Appendix Table A2 for each state.

\section{Adjusting for Selective Interstate Migration based on Educational Background}

The baseline skill measure implicitly assumes that the internal migrants from one state to another are a random sample of the residents of their state of origin. This obviously need not be the case, as the interstate migration pattern may be (very) selective. For example, graduates of Ohio universities might migrate to a very different set of states than Ohioans with less education - and it would be inappropriate to treat both flows the same.

The potential importance of selective migration can be seen from NAEP scores of population subgroups by educational background. Figure 4 displays the overall distribution of state scores for students from families where at least one parent has some kind of university education and for students from families where the parents do not have any university education. Children of parents with high educational backgrounds record much higher test scores than children of parents with lower educational backgrounds, with an average difference of over 0.6 standard deviations.

To account for selective interstate migration, we consider the migration patterns by education levels and then adjust test scores accordingly. In particular, we make the assumption that we can assign to the working-age population with a university education the test score of children with parents who have a university degree in each state of birth, and equivalently for those without a university education. From the Census data, we first compute separate population shares of university graduates and non-university graduates by state of birth for the current working-age population of each state. With these population shares, we then assign separate test scores by educational category (including those born and still living in the state as well as migrants). Note that this adjustment also deals with another aspect of selection that is often

\footnotetext{
${ }^{14}$ Across the United States as a whole, 86 percent of children aged 0-14 years still live in their state of birth, so that any measurement error introduced by this assumption should be limited. With the exception of Alaska (34 percent) and Washington, DC (54 percent) - neither of which is used in our analysis - the share is well beyond 70 percent in each individual state (own calculations based on the 2007 U.S. Census data (Ruggles et al., 2010)).
} 
ignored: It allows for selectivity of outmigration and for any differential fertility that generate differences in the cohort composition between the working-age population and those taking the NAEP tests.

The refined average scores for each state that adjust both locals and interstate migrants by education category provide cohort- and selectivity-adjusted estimates of state test scores for the working-age populations of state locals and interstate migrants.

\subsubsection{Adjustment for International Migration}

A remaining topic is how to treat immigrants - those educated in a foreign country. On average, international migration is less frequent than interstate migration. Figure 5 shows that more than 90 percent of the U.S. working-age population was born in the United States.

However, there is large state variation in this percentage for recent years: in 2007, 99 percent of the working-age population in West Virginia was born in the United States compared to only 70 percent of the working-age population in California.

The simplest approach treating immigrants is to assume that international migrants seek out places where their skills fit into the local economy. Accordingly, immigrants would be assigned the mean score of the locals in their current state of residence.

But we also have more information for immigrants. From the Census data, we know the country of origin of each immigrant. So for each country of origin, we can combine information from the major international tests - PISA, TIMSS, and PIRLS. ${ }^{15}$ We determine whether a person was educated in his or her home country by information on age of immigration into the United States. These data allow us to add in scores for the foreign-born and foreign-educated workingage population of each state.

Presumably even more than for the interstate migration, selectivity is a major concern for international immigrants. We know that international migration in particular is a highly selective process (Borjas (1987); Grogger and Hanson (2011)), implying that the mean test score of the country of birth is unlikely to accurately represent the cognitive skills of the migrant group. The United States has rather strict immigration laws, and skill-selective immigration policies represent a substantial hurdle for potential immigrants (Bertoli and Fernández-Huertas Moraga

\footnotetext{
${ }^{15}$ PISA stands for Programme for International Student Assessment, TIMSS for Trends in International Mathematics and Science Study, and PIRLS for Progress in International Reading Literacy Study. We rescale these test scores to the NAEP scale (Hanushek, Peterson, and Woessmann (2012)).
} 
(2015); Ortega and Peri (2013)). In addition, individuals self-select into migration (McKenzie, Gibson, and Stillman (2010)). Thus, for example, only the most skilled and motivated are able to gather information on possible destination countries, and only they possess skills that are rewarded in a technologically advanced foreign country. While generally framed just in terms of school attainment, the existing research on international migration mostly indicates that migrants who go to developed countries are better educated, on average, than those they leave behind (Borjas (1987); Chiswick (1999); Grogger and Hanson (2011)). Thus, while we do not have detailed information on the selectivity of migration from each country, a first variant to adjust for selective immigration - parallel to the treatment of locals and interstate migrants - is to adjust international scores by the educational distribution of the immigrant population in each state of current residence.

The past research on selective immigration, however, has mainly considered school attainment measures of skills. It is reasonable to expect that immigrants are further self-selected within schooling attainment categories. If this is true, then average test scores of the source country - either simple averages or averages by parental background - may not describe actual migrant skill levels very well. Their true skill level may exceed the home country mean test score, and even the mean test score within each educational category. To account for this selection, our second variant to adjust for selective immigration is to assign the score of the $75^{\text {th }}$ percentile of the source-country skill distribution to the international immigrant population shares. A third variant uses the $90^{\text {th }}$ percentile of the source-country skill distribution. In these latter adjustments, we thus assume that the migrants are positively selected from the sourcecountry population - i.e., that they are much more skilled than those left behind. Note that under these assumptions, immigrants from a low-performing country would still be recorded as scoring below immigrants from a high-performing country on average, and in a variety of cases including the largest immigrant group (from Mexico) below U.S. average skills. ${ }^{16}$ The skill measure with adjustment of immigrants by the $90^{\text {th }}$ percentile in their source country is reported in column 5 of Appendix Table A2.

\footnotetext{
${ }^{16}$ In the robustness analysis below, we go further by treating the Mexican immigrants as being less selected than those from other countries.
} 


\subsubsection{Backward Projection of Time-Varying Scores}

The measures so far are based on the assumption that the achievement levels produced in each state are constant over time. As a final step, we develop two methods to project the available test scores backward in time so as to allow for skill levels to differ across age cohorts of graduates from each state, one based on an extrapolation of NAEP trends and one based on a projection from available SAT scores. With the latter, we have observed state scores as far back as for those aged 53 in 2007, having to rely on trend extrapolations only for those older than that.

\section{Extrapolation of NAEP Trends}

We can potentially obtain a better estimate of older workers' skills (than obtained from relying just on the observed average state test scores) by projecting the available test scores backward in time. To accomplish this, we make use of the time patterns of scores within each state observed for the period 1992-2011, as well as the long-term national NAEP trend data available since 1978.

First, we linearly extrapolate state scores based upon the time pattern of NAEP score changes for each state over the period 1992-2011. ${ }^{17}$ Second, because we worry about the validity of the linear extrapolation over long periods, we force the state values for the period 1978-1992 to aggregate on a student-weighted basis to the national trend in NAEP performance.

This part of the extrapolation is exemplified by Figure 6, which shows both the observed data and the extrapolated state trends for two states: Massachusetts and Mississippi. Massachusetts was above the national average in 2011, but also had a steeper growth trend than the nation as a whole. As such, we shrink the extrapolated trend toward the national trend. Mississippi is different: while it also had a steeper growth trend than the nation as a whole, its scores were below the national average. Again, we shrink the extrapolation to the nationally observed trend. We do these projections for each of the 47 states in our analysis and for the separate education categories.

We lack NAEP information on performance for the period before 1978, so we use two simple variants for prior test score developments. The first variant simply holds all state scores at their estimated values for 1978. Thus, people older than 43 - the age in 2007 of an eighth-grader who took the test in 1978 - have the same test score as a 42-year-old with the same birth state.

\footnotetext{
${ }^{17}$ For the nine states that just began testing in 2003, we rely only on the pattern since then.
} 
The second variant estimates linear state trends on the state time series between 1978 and 2011 and assumes this linear development prior to 1978, starting from the projected 1978 value of each state.

We then combine the projected test score series with information on the age pattern of the working-age population from the Census. In particular, for each Census year and state of residence, we compute population shares by state of origin and education category in five-year age intervals. We then similarly construct five-year averages of the projected test score series which we match to the population shares of the appropriate age. For example, people aged 20-24 in 2007 were aged 13, the age at which the test was taken, in the years 1996-2000. Thus, we average the projected test scores between 1996 and 2000 and assign these test scores to the age group of 20-24 in 2007. Proceeding in the same way for the other age groups yields a new measure of cognitive skills for each state based on test scores that vary with age (see column 6 of Appendix Table A2).

Note that in this final measure, state scores are adjusted for differences in scores between large numbers of different subpopulations. In particular, for each state, we assign more than a thousand different scores for different subgroups of the resident population: residents from 51 states of origin times two education categories times nine age groups (918 scores) plus residents from 96 countries of origin times two education categories. Altogether over the 47 states, we thus create more than 50,000 separate test score cells (for each year for which we create the skill measure).

\section{Projection from State SAT Scores}

There is one other test score series at the state level, albeit not representative for the state population, that goes back further in time: the SAT college admission test. We obtained data on mean SAT test scores and participation by state for the period 1972 to 2013 from the College Board. We use this information to predict NAEP scores backwards on the basis of the development of SAT scores.

We cannot relate the SAT scores directly to the NAEP scores because mean SAT scores are not representative for the student population in a state (Graham and Husted (1993); Coulson 
(2014)). In particular, the mean SAT score depends strongly on the participation rate. ${ }^{18}$ A higher participation rate signals a less selective student body and therefore lower mean SAT scores. By regressing mean SAT scores on the participation rate and including state and year fixed effects, we predict mean SAT scores as if all states would have shown a participation rate that is equal to the mean U.S. participation rate (47 percent).

We use these state-specific participation-adjusted SAT scores to predict state NAEP scores before 1992. First, for each state we regress NAEP scores on participation-adjusted SAT scores in the years since 1992 when both data series are available. As the SAT is normally taken at the end of high school, we lag the SAT scores by four years to align them with the eighth-grade NAEP score. Using the coefficients from these state-specific regressions, we then predict NAEP scores from the available SAT score for the period 1968 to 1991.

The projected NAEP test score series is then used to construct alternative aggregate test scores for each state and year by applying the same algorithm for the projection of test scores by age as before. This skill measure with SAT-based adjustment is reported in column 7 of Appendix Table A2 for each state.

Table 1 provides a correlation matrix of the different skill measures. The correlations are usually very high and many exceed 0.9 , indicating that all test scores describe a similar distribution of cognitive skills. However, there are also notable differences for some states. The adjustment of international immigrants, even though a relatively small group overall, leads to somewhat lower correlations with the other measures. The correlation is least strong between measures based on backward projections of time-varying scores and measures based on constant scores. Still, the relevance of the different adjustments for understanding cross-state income differences remains to be explored.

\section{Development Accounting Framework}

We aim to evaluate the extent to which income differences across U.S. states can be accounted for by cross-state differences in human capital. This section introduces the state sample, GDP data, and the analytical framework. The next section then presents the results.

\footnotetext{
18 The College Board provided the total numbers of participation. We construct participation rates by dividing SAT participation by the number of public high school graduates in the respective year, obtained from various years of the Digest of Education Statistics.
} 


\subsection{State Sample and GDP Data}

From the 50 U.S. states, we employ 47 in our analysis. Three states are excluded from the analysis sample because of a very particular industry structure that makes their GDP unlikely to be well described by a standard macroeconomic production function based on physical and human capital. In particular, following the convention in the cross-country literature (Mankiw, Romer, and Weil (1992)), we exclude states that are abundant in natural resources, since their income will depend more on sales of raw material and less on production. Hence, we leave out Alaska and Wyoming, where 27.3 percent and 30.6 percent, respectively, of GDP comes from mining activities in 2007. All other states have mining shares of less than 12 percent.

We also exclude Delaware from the analysis. Finance and insurance in the state account for more than 35 percent of Delaware’s GDP in 2007, more than twice than in any other state. Delaware is also known as a tax haven for companies; for example, Delaware hosts more companies (ca. 945,000) than people (ca. 917,000) (Economist (2013)). Such factors reduce the dependence of the state's income on production.

For each of the 47 states in our sample, we calculate the real state GDP per capita. This measure is constructed by using nominal GDP data at the state level from the Bureau of Economic Analysis (2013b). We deflate nominal GDP by the nation-wide implicit GDP price deflator (Bureau of Economic Analysis (2013c)), following the approach of Peri (2012). We set the base year for real GDP to 2005. For real GDP per capita, we divide total real GDP by total state population. The population data also comes from the Bureau of Economic Analysis (2013a). Column 1 of Appendix Table A2 reports the real GDP per capita of each state in 2007.

While it is well known that mean real GDP per capita more than doubled from 1970 to 2007, the dispersion across states is less well known. As noted earlier, there was a \$30,000 mean difference between the richest and poorest states in 2007. Figure 1 also reveals that the dispersion across states has increased substantially. In real dollar terms, the standard deviation across states increased from \$2,895 in 1970 to \$6,388 in 2007. This dispersion motivates the analysis of the underlying causes of the differences.

State incomes are strongly correlated with both measures of human capital. Figures 7 and 8 show scatterplots of the association across states of log GDP per capita in 2007 with average years of schooling and with the skill measure that adjusts for selective interstate and international migration (the latter by the $90^{\text {th }}$ percentile), respectively. The cross-state correlations are 0.521 
between log GDP per capita and average years of schooling and 0.574 between log GDP per capita and the skill measure. Similarly, average years of schooling and the skill measure are strongly correlated at 0.704 (see Appendix Figure A1). To go beyond these correlations and provide an indication of the causal contributions of the different human capital components to income differences across states, we next turn to a standard development accounting framework.

\subsection{Analytical Framework}

Development accounting provides a means of decomposing variations in the level of GDP per capita between states into the different components of input factors of a macroeconomic production function. ${ }^{19}$ Our basic development accounting framework begins with an aggregate Cobb-Douglas production function:

$$
Y=(h L)^{1-\alpha} K^{\alpha} A^{\lambda}
$$

where $Y$ is GDP, $L$ is labor, $h$ is a measure of labor quality or human capital per worker, and $K$ is capital. $A^{\lambda}$ describes total factor productivity. With Harrod-neutral productivity $(\lambda=1-\alpha)$, we can express the production function in per capita terms as:

$$
\frac{Y}{L} \equiv y=h\left(\frac{k}{y}\right)^{\alpha /(1-\alpha)} A
$$

where $k \equiv \frac{K}{L}$ is the capital-labor ratio.

The decomposition of variations in per-capita production is then straightforward. Taking logarithms, the covariances of log GDP per capita with the input factors are additively separable (Klenow and Rodriquez-Clare (1997)):

$$
\operatorname{var}(\ln (y))=\operatorname{cov}(\ln (y), \ln (h))+\operatorname{cov}\left(\ln (y), \ln \left(\left(\frac{k}{y}\right)^{\alpha /(1-\alpha)}\right)\right)+\operatorname{cov}(\ln (y), \ln (A))
$$

Dividing by the variance of GDP per capita puts each component in terms of its proportional contribution to the variance of income:

$$
\frac{\operatorname{cov}(\ln (y), \ln (h))}{\operatorname{var}(\ln (y))}+\frac{\operatorname{cov}\left(\ln (y), \ln \left(\left(\frac{k}{y}\right)^{\alpha /(1-\alpha)}\right)\right)}{\operatorname{var}(\ln (y))}+\frac{\operatorname{cov}(\ln (y), \ln (A))}{\operatorname{var}(\ln (y))}=1
$$

\footnotetext{
${ }^{19}$ Caselli (2005) and Hsieh and Klenow (2010) provide additional detail on the approach of development accounting.
} 
Our interest is the importance of human capital for income differences. Thus, we focus on the first term of this decomposition, the share of the income variance due to human capital, $\frac{\operatorname{cov}(\ln (y), \ln (h))}{\operatorname{var}(\ln (y))}$.

To check the robustness of our results, we also look at how well we can account for the extremes of GDP per capita of the five states with the highest GDP per capita and the five states with the lowest GDP per capita (Hall and Jones (1999)). We will refer to this measure as the five-state measure:

$$
\frac{\ln \left[\left(\Pi_{i=1}^{5} X_{i} / \Pi_{j=n-4}^{n} X_{j}\right)^{1 / 5}\right]}{\ln \left[\left(\prod_{i=1}^{5} y_{i} / \prod_{j=n-4}^{n} y_{j}\right)^{1 / 5}\right]}+\frac{\ln \left[\left(\prod_{i=1}^{5} A_{i} / \prod_{j=n-4}^{n} A_{j}\right)^{1 / 5}\right]}{\ln \left[\left(\prod_{i=1}^{5} y_{i} / \prod_{j=n-4}^{n} y_{j}\right)^{1 / 5}\right]}=1
$$

where $i$ and $j$ are states which are ranked according to their GDP per capita, $i, \ldots, j, \ldots, n$ among the total of $n$ states and $X$ refers to the two factor input components (human and physical capital) as above. Using this decomposition method, we can account for the contribution of the difference in human capital for the difference in GDP per capita between the five richest and five poorest states. $^{20}$

\section{The Contribution of Human Capital to State Income}

We are now in a position to decompose state variations in GDP per capita into contributions that can be accounted for by differences in the two components of human capital, years of schooling and cognitive skills. For that, we introduce the different test score specifications developed in section 2.3 into the aggregate human capital measure derived in section 2.1 and apply it in the development accounting framework of section 3.2. ${ }^{21}$

${ }^{20}$ The five richest states in 2007 are Connecticut, New York, Massachusetts, New Jersey, and California. The five poorest states in 2007 are West Virginia, Mississippi, Arkansas, Kentucky, and Alabama.

${ }^{21}$ For completeness, we can report information about the full decomposition of income differences even though we concentrate completely on the human capital component. Using the 2000 value of state physical capital from Turner, Tamura, and Mulholland (2013) in our development accounting analysis and assuming a production elasticity of physical capital of $\alpha=1 / 3$, differences in physical capital can account for 14.1 percent of the cross-state income variation with the covariance measure and 18.1 percent with the five-state measure. With 27.3 and 36.5 percent, respectively, attributed to differences in our preferred human capital measure with the two decomposition methods (see below), the unexplained part of the income variation that could be attributed to differences in total factor productivity would be 58.6 percent with the covariance measure and 45.4 percent with the five-state measure. 


\subsection{Basic Results}

Table 2 shows the results of the development accounting exercise for different basic test score specifications. At this point, we focus on GDP per capita in 2007 (although results for 2010 are very similar). Subsequently, we consider earlier periods.

\section{Baseline Test Score Specification}

The contribution of human capital to state differences in the level of income can be separated into quantitative (attainment) and qualitative (cognitive skills) dimensions. Based on a rate of return per year of schooling of 10 percent, state differences in average years of schooling of the working-age population account for 11.7 percent of the cross-state variance in GDP per capita in 2007. ${ }^{22}$ This component of our human capital measure does not change in most of our subsequent analysis, so its contribution stays the same.

For the baseline measure of the cognitive skill component of human capital, we begin with the raw math test score data for states and proceed to refine the skill estimates of the workingage population. The baseline specification adjusts the local average test score for the portion of the working-age population that is made up of interstate migrants. Locals and international migrants receive the test score of their state of residence, and interstate migrants receive the test score of their state of birth.

State differences in this baseline cognitive skill measure account for 6.7 percent of the variance in GDP per capita across states, based on a return per standard deviation in test scores of 20 percent. Differences in aggregate human capital of the working-age population thus account for 18.4 percent of the variation in GDP per capita in this specification.

The five-state measure provides a slightly different perspective on income variations. From this, we see that human capital can account for 25.9 percent of the variation of GDP per capita between the five richest and the poorest states. Across these state extremes, 10.9 percent of the variation is accounted for by differences in test scores and 14.9 percent is accounted for by differences in years of schooling.

\footnotetext{
${ }^{22}$ Reported standard errors are bootstrapped with 1,000 replications throughout.
} 


\section{Adjustment of Test Scores for Selective Interstate Migration}

The remainder of Table 2 provides results for the more refined test score measures of the human capital of the working-age population in each state. Since the measure of school attainment is held constant, it accounts for a constant portion of the variance in income, and we focus on how income variations are related to alternative test score measures.

The distribution of skills in the labor force differs from that of students because of both selective migration and heterogeneous fertility. The most straightforward step is adjusting the test scores of locals for their educational background, i.e., whether the working-age locals have a university degree or not. With this refinement, differences in cognitive skills account for 7.8 percent of the state variation in GDP per capita.

Similarly adjusting the scores of interstate migrants by educational background raises the explanatory value of test scores to 8.9 percent. Thus, after adjusting scores of the U.S.-born population for education levels, we account for 20.6 percent of the total variation in GDP per capita with human capital differences across states. Of the variation due to human capital, then, 43 percent derives from variations in test scores and 57 percent from variations in years of schooling.

In terms of the variation in income between the richest and poorest five states, adjusting the test scores of locals and interstate migrants by education category raises the explained income variation to 13.1 percent, or close to equal the impact of variations in years of schooling.

\section{Adjustment of Test Scores for International Migration}

We now turn to the skills of immigrants from abroad. The prior estimates simply assigned international migrants the average test score of their state of residence. The most obvious refinement is to adjust the test score of international migrants by using the average test score of their country of birth by education category. But, somewhat surprisingly, the covariance measure shows a large drop for the test score to 3.8 percent, and the estimate is no longer statistically different from zero. ${ }^{23}$

The most obvious explanation for the poor performance of the human capital measure in this first attempt to account for international migration is that the quality measure for immigrants is very error-prone. While the measure adjusts for the educational distribution of immigrants, this

\footnotetext{
${ }^{23}$ Results are similar when using the average test score of the country of birth without adjustment for education category.
} 
adjustment is likely to be insufficient. As argued in section 2.3.3, a substantial literature has shown that immigrants into developed countries tend to be strongly positively selected from their country of origin. This may be due not only to the self-selection of better-skilled and bettermotivated individuals into migration but also U.S. immigration policies. If this is true, then it is not surprising that averages of the test scores of the source country, even if adjusted for parental background, do a poor job in describing migrant skill levels. The true skill levels should exceed the home country mean test score, and even the mean test score within each educational category. To account for this selection, we assign international migrants the $75^{\text {th }}$ percentile of their home country test score distribution in one specification and the $90^{\text {th }}$ percentile in another specification.

Basing the estimates of immigrant skills on this assumption of highly selective international migration flows provides a much stronger picture of the importance of human capital for variations in state income. According to the $90^{\text {th }}$ percentile estimate of selection, test score variation accounts for 11.1 percent of the variation in GDP per capita - almost the same as school attainment. The five-state measure shows total human capital accounting for close to onethird of the variation in state incomes, with the test score component being slightly larger than the years of schooling component.

Mexicans constitute a special group of immigrants in the United States, constituting close to one quarter of the total immigrant population (see Appendix Table A3). Given the close geographic proximity and the substantial differences in economic development, it is also reasonable to assume that the migrant population from Mexico may show different selection patterns than the migrant population from most other countries. Still, existing research on the selectivity of Mexican migrants comes to very different conclusions about the extent to which Mexican migrants are selected from their home-country population (e.g., Chiquiar and Hanson (2005); Fernández-Huertas Moraga (2011)). The only study that has information on cognitive skills finds that Mexican migrants to the United States are not a selected subgroup of their home country population (Kaestner and Malamud (2014)). Nonetheless, when we assign Mexicans the mean score of their home country and all other immigrants the $90^{\text {th }}$ percentile, results are close to the specification that adjusts also Mexicans for the $90^{\text {th }}$ percentile, despite the fact that Mexicans constitute by far the largest group of immigrants to the United States. Thus, our development accounting estimates are not much affected by the specific treatment of Mexican immigrants. 


\subsection{An Historical Picture of the Contribution of Human Capital}

It is possible to conduct development accounting analysis for earlier decades, building on the picture of the state working-age population available in prior decennial censuses. Table 3 reports the covariance measure results of development accounting analyses going back to 1970 . In constructing the skill measure for the earlier years, the population shares of state locals, interstate migrants, and international immigrants by education categories of each state are taken from the respective year. The test scores that are assigned to the different groups, though, still come from the assumption of a constant test score level being produced for each education category in the school system of each state.

Three broad patterns of results emerge in the historical picture. First, while there is some variation over time, the importance of human capital in accounting for state income variations remains quite similar over the four decades of the analysis. The total variation due to human capital remains between 20 percent and 25 percent.

Second, the proportion attributed to years of schooling, or school attainment, is consistently higher in earlier decades than in 2007. In 1970, 18.9 percent of state income variations were related to years of schooling; this fell to 11.7 percent in 2007.

Third, independent of the precise approach to estimating test scores for locals, interstate migrants, and international migrants, the proportion of variations in state GDP per capita accounted for by test scores falls as we move back from 2007. This changing pattern is particularly important as we consider how best to approach measuring human capital. While this result might arise if there was less demand for skilled workers in the past, there is a real possibility that the measurement errors in cognitive skills become more important for earlier generations of workers. Indeed, in the earliest two years analyzed in Table 3 - i.e., 1970 and 1980 - none of a state's workers actually participated in any of the NAEP testing.

So far, we have relied upon a constant achievement level for each state, in part, because of the relative importance of between-state variation in test scores. But this assumption may well fail the further back in time state income patterns are investigated. Therefore, we now turn to our backward extrapolations of test scores by age. 


\subsection{Age Projection of Historical Achievement Patterns}

The alternative to assuming a constant achievement level for each state is to project achievement levels backward, either based on observed state trends in NAEP achievement or additionally using earlier information on SAT scores.

\section{Extrapolation of NAEP Trends}

We begin with the extrapolation of trends based on observed NAEP scores for states and for the nation (see section 2.3.4 above). The state-level time patterns are observed from 1992 to 2011 and the long-term national NAEP trend data go back to 1978. In the results reported here, we assume linear state trends before 1978. We perform the projections for each of the 47 states in our analysis and for the separate education categories. Because the projections include obvious estimation error, we consider the development accounting exercise first without and then with division by education category.

Table 4 shows the results of the 2007 development accounting for the test scores projected by five-year age cohorts. The first line depicts the baseline specification from above (Table 2) as a comparison. Once we adjust the test scores of locals for the projections by age category, the variation in GDP per capita accounted for by the test scores rises to 10.1 percent, yielding a total due to human capital of 21.8 percent.

When the interstate migrants are also adjusted by age category, the share related to test scores increases to 11.9 percent. That figure is slightly larger than the estimated 11.1 percent seen in the prior results for the average test scores under the full $90^{\text {th }}$ percentile adjustment for international migrants. Now assigning the same $90^{\text {th }}$ percentile test scores to international migrants, in addition to the projected test scores by age category for locals and interstate migrants, suggests that 25.8 percent of the variation in GDP per capita can be accounted for by variation in human capital: 14.1 percent from test scores and 11.7 percent from years of schooling.

In Table 5, we push the projections one step further and use projected test scores adjusted for both age and education category. Adjusting both locals and interstate migrants for estimated scores by age-education groups increases the portion of income variation attributed to test scores to 13.4 percent - greater than the 11.7 percent that years of schooling account for. 
Our preferred specification is the one that in addition to the adjusting for the selectivity of interstate migration by time-varying education-specific test scores also incorporates an adjustment of the test scores of international migrants using the $90^{\text {th }}$ percentile of their countryof-birth test score distribution. In this preferred specification, shown in the last row of Table 5, we now attribute 15.6 percent of income variation to skill differences across states. Total human capital accounts for 27.3 percent of the variation in GDP per capita across states.

While not emphasized, the differences in the extremes of the state income distribution as seen in the five-state analysis uniformly show a larger role of human capital. With the full projections of skills, the five-state measure yields an even larger proportion than the covariance measure: 36.5 percent of explained variation, with 21.6 percentage points attributed to differences in cognitive skills and 14.9 percentage points attributed to differences in years of schooling.

\section{Projection from State SAT Scores}

A check on the reliability of the age projections based on NAEP trends comes from the test score projections based on participation-adjusted SAT scores, which are observed at the state level back to 1968. Unfortunately, SAT scores are not available by educational background, so we cannot perform the selectivity adjustment by educational categories here.

The first column of Table 6 reproduces the respective development accounting results based on the extrapolated NAEP trends by age (but not educational categories) from Table 4 for comparison. The second column reports the respective development accounting results based on the SAT projections. The results from this very different projection approach to constructing test scores before 1992 closely resemble our main results, providing confidence in the results based

on time-varying test scores. ${ }^{24}$ However, the estimates based on SAT projections are slightly less precise, as indicated by a larger standard error.

We do not have information on test score trends before the first observed scores for either case: 1978 in the case of national NAEP and 1968 in the case of SAT. While the specifications reported so far assume backward projections of observed linear state trends before the first observed test score, an alternative is to simply assume that state scores remained constant before

\footnotetext{
${ }^{24}$ Note that test scores between 1992 and 2011 are the same for the two projections.
} 
the first observed score. As seen in the final columns of Table 6, development accounting estimates are somewhat lower, but do not differ markedly in this specification.

\subsection{Sensitivity Analysis}

We close the development accounting analysis with evidence on the sensitivity of the accounting results across different subjects, alternative return parameters, and for different numbers of states included in the top-bottom comparison of states.

While our analysis has focused on achievement in math throughout, we can also perform the same analysis for reading, where state-specific scores are available just from 1998 onwards. Results are quite similar: The 15.6 percent of the cross-state income variation attributed to math test scores in our preferred specification corresponds to 14.4 percent based on the reading test scores. When math and reading test scores are combined into one measure, the value is 15.3 percent.

As discussed in section 2.1, we chose a return of $w=0.2$ per standard deviation in test scores and a return of $r=0.1$ per year of schooling as parameters in our main calibration. Table 7 reports results for alternative parameter values that are one quarter below and above, respectively, for each for the two parameters. With the different parameter values, the contribution attributed to test scores ranges from 11.7 to 19.5 percent and the contribution attributed to years of schooling ranges from 8.8 to 14.6 percent.

So far, we use common return parameters for different levels of the human capital measures. It has been argued, however, that technological change over recent decades has raised the returns to human capital at the higher end compared to at the lower end. While we do not have access to micro estimates of returns to cognitive skills that vary across skill levels, we can use the IPUMS data to estimate returns to years of schooling that differ for different levels of education. Estimating the average return to years of schooling in the standard Mincer way on the 2007 IPUMS data yields a return estimate of $r=0.124$, or 24 percent higher than the $r=0.1$ we assume in our calibration. But when returns are allowed to differ between years of schooling at the tertiary and non-tertiary levels, the return to non-tertiary years of schooling is estimated at 0.057 and the return to tertiary years of schooling at 0.157 . That is, returns to years of schooling appear to be substantially higher at higher rather than lower levels of education. 
Results using these level-specific returns to years of schooling in our development accounting analysis are reported at the bottom of Table 7. Interestingly, the share of state income variation attributed to state differences in years of schooling rises from 14.5 percent with the average return estimate (when estimated from the current IPUMS data) to 18.0 percent with the level-specific return estimates. Together with the cognitive skill component, this raises the total contribution of human capital to 33.6 percent. This suggests that our main analysis potentially represents an underestimation of the true contribution of human capital to income differences across states.

Finally, the choice of five - rather than some other number of - states at the top and bottom of the state income distribution to estimate the five-state measure is somewhat arbitrary. Appendix Table A4 shows, however, that the qualitative results of this measure are quite similar when using three or seven states at the top and bottom of the distribution instead to estimate this measure.

\section{Growth Accounting}

The analysis so far has considered income levels across the U.S. states. We close with a brief corresponding growth accounting exercise that analyzes the extent to which changes in human capital can consistently account for differences in observed growth rates across U.S. states over the past decades.

\subsection{Introducing Mincer-Type Human Capital into Growth Accounting Analysis}

We begin with the derivation of a growth accounting decomposition in our model framework. We show that both years of schooling and test scores have a straightforward mapping into growth rates once a Mincer-type specification of aggregate human capital is applied.

Consider again a standard Cobb-Douglas production function:

$$
Y=(h L)^{1-\alpha} K^{\alpha} A
$$


which in growth accounting analyses is usually taken to exhibit Hicks-neutral productivity. ${ }^{25}$ This can be written in per-capita terms as:

$$
y=\frac{(h L)^{1-\alpha} K^{\alpha}}{L^{\alpha} \mathrm{L}^{1-\alpha}} A=\mathrm{h}^{1-\alpha} k^{\alpha} A
$$

Accordingly, average annual growth in GDP per capita can be decomposed into three components - the contributions of human capital, physical capital, and total factor productivity, respectively - as follows:

$$
g \equiv \frac{1}{t} \Delta \ln y=\frac{1}{t}(1-\alpha) \Delta \ln h+\frac{1}{t} \alpha \Delta \ln k+\frac{1}{t} \Delta \ln A
$$

As before, human capital per capita is given by the Mincer-type specification augmented by cognitive skills in equation $1, h=e^{r S+w T}$. Then, the contribution of human capital to the average annual rate of growth has a straightforward expression:

$$
\begin{gathered}
\frac{1}{t}(1-\alpha) \Delta \ln h=\frac{1}{t}(1-\alpha)\left[\ln h_{t}-\ln h_{0}\right]=\frac{1}{t}(1-\alpha)\left[\left(r S_{t}+w T_{t}\right)-\left(r S_{0}+w T_{0}\right)\right] \\
=\frac{1}{t}(1-\alpha) r \Delta S+\frac{1}{t}(1-\alpha) w \Delta T
\end{gathered}
$$

That is, the absolute change in years of schooling, as well as the absolute change in test scores, have a direct linear mapping into economic growth rates. The mapping is given by the standard parameterization of the share of capital in income which is usually assumed at $\alpha=1 / 3$, the earnings rate of return to years of schooling $r=0.1$, and the earnings returns to cognitive skills $w=0.2$ per standard deviation in test scores.

For example, if the average years of schooling $S$ of a population were to increase by half a year over a 10-year period, the contribution to average annual growth in GDP per capita $g$ would be given as:

$$
\frac{1}{t}(1-\alpha) r \Delta S=\frac{1}{10} * \frac{2}{3} * 0.1 * 0.5=0.33 \%
$$

That is, by assuming the production function with the standard parameterization, we can infer that an increase in a population's average schooling by half a year, obtained over one decade, would account for one third of a percentage point average annual growth over the decade.

${ }^{25}$ See Gundlach, Rudman, and Woessmann (2002) on the relevance of the differences in the different neutrality concepts. 
Similarly, if the average educational achievement level $T$ of a population were to increase by 25 percent of a standard deviation over a 10-year period, the contribution to average annual growth in GDP per capita $g$ would be given as:

$$
\frac{1}{t}(1-\alpha) w \Delta T=\frac{1}{10} * \frac{2}{3} * 0.2 * 0.25=0.33 \%
$$

That is, again assuming the production function with the standard parameterization, we can infer that an increase in a population's educational achievement by 0.25 standard deviations, obtained over one decade, would also account for one third of a percentage point average annual growth over the decade.

\subsection{Growth Accounting for the United States}

Table 8 provides some basic results of growth accounting analyses for the United States over recent decades. Average annual growth in GDP per capita amounted to 2.2 percent over the 1970s, 2.4 percent over the 1980s, 2.5 percent over the 1990s, and 1.5 percent over the 2000s (excluding the crisis years).

Average years of schooling in the working-age population increased from 11.1 in 1970 to 12.0 in 1980, 12.5 in 1990, 12.8 in 2000, and 13.04 in $2007 .{ }^{26}$ Based on the derivation above, these increases in average years of schooling can account for 0.6 percent average annual growth in GDP per capita over the 1970s, 0.4 percent over the 1980s, and 0.2 percent over the 1990s and the 2000s.

Quantifying changes in the cognitive skills of the working-age population over time is much harder. But to pin down magnitudes, consider the change in NAEP test scores as derived in Hanushek, Peterson, and Woessmann (2012). For the U.S. as a whole, test scores increased by 2.6 percent of a standard deviation per year on average over the period $1992-2011 .{ }^{27}$ If we were to assume that the average achievement of the working-age population increased by the same amount, this would account for 0.35 percent of average annual growth in GDP per capita based on the derivation above.

Over the entire period 1970-2007 when growth was 2.2 percent, the total change in human capital accounts for 0.7 percent average annual growth, or close to a third of the total observed

\footnotetext{
${ }^{26}$ Own calculations based on Ruggles et al. (2010).

27 This average annual change is derived as the coefficient estimate on years in a regression that has standardized test scores as the dependent variable.
} 
growth in the United States. Changes in test scores and changes in years of schooling contribute about equally to this number.

\subsection{Growth Accounting for Individual States}

The prior growth accounting for the nation can be extended to look at growth within each of the states. There is considerable heterogeneity across states in growth rates since 1970: seven states have real growth of GDP per capita that exceeds 2.5 percent annually, while another seven states have growth less than 2 percent per year.

If we decompose these different growth experiences in the same way as the national experience, we see even further heterogeneity in the role of human capital and other factors. Figure 9 shows growth accounting results separately for each state. ${ }^{28}$ It is obvious that growth in years of schooling and in test scores can account for a substantial part of the overall economic growth between 1970 and 2007 in all states, but there appears to be no simple pattern. For example, in Iowa and Nebraska, two states with above average growth, test score growth explains little. In contrast, Virginia and Massachusetts are driven significantly more by human capital growth and especially test score growth.

These estimates are surely quite error prone, in particular because of the lack of data on test score trends for the working-age population. Nonetheless, they provide data for further investigations of growth dynamics.

\section{Conclusions}

Variations in state income across the United States remain large and important. Indeed the variation of state GDP per capita appears to have expanded in recent decades even in the face of substantial migration of the population. At the same time, the sources of these variations are imperfectly understood.

This paper focuses on the contribution of human capital to the variations in state GDP per capita. Almost all states, in their efforts to foster economic development, introduce policies to improve the skills of their youth (the future labor force), to attract skilled people from other states or countries, and to otherwise improve the human capital of their labor force. One might

\footnotetext{
${ }^{28}$ Detailed results of the growth accounting by state are provided in Appendix Table A5.
} 
expect population shifts across the states to equalize incomes across states and to blunt the impact of human capital policies on state development, but the net result remains uncertain.

We pursue development accounting analyses to decompose variations in state GDP per capita. The decomposition relies on external estimates of the key parameters of a neoclassical aggregate production function. By its nature, this accounting is conservative, relying on just the accumulation of human capital and not allowing for skills to directly affect growth as in endogenous growth models.

The central empirical challenge is developing human capital measures for the different states. Following research on international differences in income and growth, we are particularly interested in the role of cognitive skills. While it is easy to measure the school attainment of the working-age population of each state, it is much more challenging to measure the cognitive skills of each state's working-age population.

We base our cognitive skill measure on test scores of the school-age population in each state and in each country internationally. The challenge is to reconcile the different locations of schooling due to migration and the changing scores of different generations of students in our assessment of the skills of the current working-age population in each state. We do this by working with each person's state of birth as the main indicator of likely schooling location. This, in turn, provides the skill mapping for the current working-age population. But prior analyses of migration have made clear that we must also account for the selectivity of migration.

Our analysis confirms the importance of a detailed identification of cognitive skills for the working-age population. In our preferred model, we allow for differences in the cognitive skills of the working-age population according to education levels, incorporating selective migration from other states and other countries. Because the test score information by state of birth is unavailable for older workers in each state, we use time patterns of state and national achievement scores to extrapolate back in time and, thereby, to estimate the cognitive skills accrued by older workers when they were in school.

Our estimates of human capital combine cognitive skills with school attainment of the working-age population. We use market prices estimated in micro studies for each of the two in order to aggregate the two components of human capital.

Our results indicate that at least one-fifth to one-third of the overall variation in state GDP per capita is attributable to variations in human capital across states. The lower end of the range 
reflects decompositions based on the crudest estimates of the cognitive skills of the state population. The importance of cognitive skills to economic performance rises with the precision of the derivation. Variations in cognitive skills and variations in school attainment contribute in approximately equal measure to the variations attributable to human capital. Growth accounting exercises indicate similar results for the role of human capital in accounting for observed U.S. growth rates over the past several decades.

These estimates appear remarkably large for a variety of reasons. First, the United States is known for the openness of its labor and capital markets, which allow free movement of workers across state lines. This dynamic would presumably even out the distribution of human capital and lead to convergence of state incomes. Second, the estimation of state human capital stocks is subject to error, even in our more refined estimates. There is measurement error in the student test scores themselves, and the possibility to adjust for selective migration is imperfect given available data. This inaccuracy most likely drives down the variations in income that can be attributed to human capital. As noted, the contribution of human capital is consistently larger when the most refined estimates of skills are used.

Furthermore, the chosen simple neoclassical modeling framework likely underestimates the contribution of human capital. Allowing for complementarities of human capital with physical capital and with unskilled labor may lead to a significant increase in the income differences attributed to human capital (Jones (2014)). Furthermore, human capital may have indirect effects on output by facilitating access to the best technologies and by driving technological change, making total factor productivity a function of human capital. Thus, while our results highlight the importance of improved measurement of human capital, in many ways the provided estimates may constitute a lower bound of the true contribution of human capital to income differences across U.S. states.

The importance of human capital, and particularly cognitive skills, provides support for policies of various states that are aimed at improving the quality of schools. While any details of policy considerations are beyond the scope of this analysis, the value of improving skills has clear implications for state incomes. 


\section{References}

Aghion, Philippe, Leah Boustan, Caroline M. Hoxby, and Jérôme Vandenbussche. 2009. "The causal impact of education on economic growth: Evidence from the U.S." Mimeo. Department of Economics: Harvard University (March).

Aghion, Philippe, and Peter Howitt. 1998. Endogenous growth theory. Cambridge, MA: MIT Press.

Altonji, Joseph G., and Charles R. Pierret. 2001. "Employer learning and statistical discrimination." Quarterly Journal of Economics 116, no. 1 (February): 313-350.

Autor, David H., David Dorn, and Gordon H. Hanson. 2013. "The China syndrome: Local labor market effects of import competition in the United States." American Economic Review 103, no. 6: 2121-2168.

Barro, Robert J. 1991. "Economic growth in a cross section of countries." Quarterly Journal of Economics 106, no. 2 (May): 407-443.

Barro, Robert J., and Xavier Sala-i-Martin. 1992. "Convergence." Journal of Political Economy 100, no. 2 (April): 223-251.

Bertoli, Simone, and Jesús Fernández-Huertas Moraga. 2015. "The size of the cliff at the border." Regional Science and Urban Economics 51: 1-6.

Bils, Mark, and Peter J. Klenow. 2000. "Does schooling cause growth?" American Economic Review 90, no. 5 (December): 1160-1183.

Bishop, John H. 1989. "Is the test score decline responsible for the productivity growth decline?" American Economic Review 79, no. 1: 178-197.

Borjas, George J. 1987. "Self-selection and the earnings of immigrants." American Economic Review 77, no. 4 (September): 531-553.

Borjas, George J., Stephen G. Bronars, and Stephen J. Trejo. 1992. "Self-selection and internal migration in the United States." Journal of Urban Economics 32, no. 2: 159-185.

Bound, John, Jeffrey Groen, Gábor Kézdi, and Sarah Turner. 2004. "Trade in university training: cross-state variation in the production and stock of college-educated labor." Journal of Econometrics 121, no. 1-2: 143-173.

Bowles, Samuel, Herbert Gintis, and Melissa Osborne. 2001. "The determinants of earnings: A behavioral approach." Journal of Economic Literature 39, no. 4 (December): 1137-1176.

Bureau of Economic Analysis. 2013a. "Annual state personal income and employment, SA1-3 Personal income summary." http://www.bea.gov/iTable/iTableHtml.cfm?reqid=70\&step=1\& isuri=1. U.S. Department of Commerce.

Bureau of Economic Analysis. 2013b. "GDP per state, Regional Economic Accounts." http://www.bea.gov/regional/downloadzip.cfm. U.S. Department of Commerce.

Bureau of Economic Analysis. 2013c. "Implicit price deflator for GDP, National Income and Product Account Tables, Table 1.1.9." http://www.bea.gov/iTable/iTable.cfm?reqid=9\& $\underline{\text { step }=3 \& \text { isuri }=1 \& 903=13 \# \text { reqid }=9 \& \text { step }=3 \& \text { isuri }=1 \& 903=13}$. U.S. Department of Commerce. 
Card, David. 1999. "The causal effect of education on earnings." In Handbook of Labor Economics, edited by Orley Ashenfelter and David Card. Amsterdam: North-Holland: 18011863.

Card, David, and Alan B. Krueger. 1992. "Does school quality matter? Returns to education and the characteristics of public schools in the United States." Journal of Political Economy 100, no. 1 (February): 1-40.

Caselli, Francesco. 2005. "Accounting for cross-country income differences." In Handbook of Economic Growth, edited by Philippe Aghion and Steven N. Durlauf. Amsterdam: North Holland: 679-741.

Caselli, Francesco. 2014. "The Latin American efficiency gap." CFM Discussion Paper 2014-21. London: Centre for Macroeconomics.

Chetty, Raj, John N. Friedman, Nathaniel Hilger, Emmanuel Saez, Diane Whitmore Schanzenbach, and Danny Yagan. 2011. "How does your kindergarten classroom affect your earnings? Evidence from Project STAR." Quarterly Journal of Economics 126, no. 4 (November): 1593-1660.

Chiquiar, Daniel, and Gordon H. Hanson. 2005. "International migration, self-selection, and the distribution of wages: Evidence from Mexico and the United States." Journal of Political Economy 113, no. 2: 239-281.

Chiswick, Barry R. 1999. "Are immigrants favorably self-selected?" American Economic Review 89, no. 2 (May): 181-185.

Ciccone, Antonio, and Elias Papaioannou. 2009. "Human capital, the structure of production, and growth." Review of Economics and Statistics 91, no. 1 (February): 66-82.

Coulson, Andrew J. 2014. "Drawing meaningful trends from the SAT." Cato Working Papers Washington, DC: Cato Institute (March).

Dahl, Gordon B. 2002. "Mobility and the return to education: Testing a Roy model with multiple markets." Econometrica 70, no. 6: 2367-2420.

Economist. 2013. How to stop companies and people dodging tax, in Delaware as well as Grand Cayman. The Economist, February 16.

Erosa, Andrés, Tatyana Koreshkova, and Diego Restuccia. 2010. "How important is human capital? A quantitative theory assessment of world income inequality." Review of Economic Studies 77, no. 4 (October): 1421-1449.

Evans, Paul, and Georgios Karras. 2006. "Do economies converge? Evidence from a panel of U.S. states." Review of Economics and Statistics 78, no. 3: 384-388.

Fernández-Huertas Moraga, Jesús. 2011. "New evidence on emigrant selection." Review of Economics and Statistics 93, no. 1 (February): 72-96.

Gennaioli, Nicola, Rafael La Porta, Florencio Lopez-de-Silanes, and Andrei Shleifer. 2013. "Human capital and regional development." Quarterly Journal of Economics 128, no. 1 (February): 105-164.

Glaeser, Edward L., Giacomo A. M. Ponzetto, and Kristina Tobio. 2014. "Cities, skills and regional change." Regional Studies 48, no. 1: 7-43. 
Glaeser, Edward L., and Albert Saiz. 2004. "The rise of the skilled city." Brookings-Wharton Papers on Urban Affairs 5: 47-105.

Goldin, Claudia, and Lawrence F. Katz. 2008. The race between education and technology. Cambridge, MA: Harvard University Press.

Graham, Amy E., and Thomas A. Husted. 1993. "Understanding state variations in SAT scores." Economics of Education Review 12, no. 3 (September): 197-202.

Grogger, Jeffrey, and Gordon H. Hanson. 2011. "Income maximization and the selection and sorting of international migrants." Journal of Development Economics 95, no. 1: 42-57.

Gundlach, Erich, Desmond Rudman, and Ludger Woessmann. 2002. "Second thoughts on development accounting." Applied Economics 34, no. 11: 1359-1369.

Haider, Steven, and Gary Solon. 2006. "Life-cycle variation in the association between current and lifetime earnings." American Economic Review 96, no. 4: 1308-1320.

Hall, Robert E., and Charles I. Jones. 1999. "Why do some countries produce so much more output per worker than others?" Quarterly Journal of Economics 114, no. 1: 83-116.

Hanushek, Eric A. 2011. "The economic value of higher teacher quality." Economics of Education Review 30, no. 3 (June): 466-479.

Hanushek, Eric A., and Dennis D. Kimko. 2000. "Schooling, labor force quality, and the growth of nations." American Economic Review 90, no. 5 (December): 1184-1208.

Hanushek, Eric A., Paul E. Peterson, and Ludger Woessmann. 2012. Achievement growth: International and U.S. state trends in student achievement. Cambridge, MA: Program on Education Policy and Governance, Harvard Kennedy School (July).

Hanushek, Eric A., Guido Schwerdt, Simon Wiederhold, and Ludger Woessmann. 2015. "Returns to skills around the world: Evidence from PIAAC." European Economic Review 73: 103-130.

Hanushek, Eric A., and Ludger Woessmann. 2008. "The role of cognitive skills in economic development." Journal of Economic Literature 46, no. 3 (September): 607-668.

Hanushek, Eric A., and Ludger Woessmann. 2012a. "Do better schools lead to more growth? Cognitive skills, economic outcomes, and causation." Journal of Economic Growth 17, no. 4 (December): 267-321.

Hanushek, Eric A., and Ludger Woessmann. 2012b. "Schooling, educational achievement, and the Latin American growth puzzle." Journal of Development Economics 99, no. 2 (November): 497-512.

Hanushek, Eric A., and Lei Zhang. 2009. "Quality-consistent estimates of international schooling and skill gradients." Journal of Human Capital 3, no. 2 (Summer): 107-143.

Heckman, James J., John Eric Humphries, and Nicholas S. Mader. 2011. "The GED." In Handbook of the Economics of Education, edited by Eric A. Hanushek, Stephen Machin, and Ludger Woessmann. Amsterdam: North Holland: 423-483.

Heckman, James J., Anne Layne-Farrar, and Petra Todd. 1996. "Human capital pricing equations with an application to estimating the effect of schooling quality on earnings." Review of Economics and Statistics 78, no. 4 (November): 562-610. 
Hendricks, Lutz. 2002. "How important is human capital for development? Evidence from immigrant earnings." American Economic Review 92, no. 1 (March): 198-219.

Higgins, Matthew J., Daniel Levy, and Andrew T. Young. 2006. "Growth and convergence across the United States: Evidence from county-level data." Review of Economics and Statistics 88, no. 4: 671-681.

Hsieh, Chang-Tai, and Peter J. Klenow. 2010. "Development accounting." American Economic Journal: Macroeconomics 2, no. 1: 207-223.

Jaeger, David A. 1997. "Reconciling the old and new Census Bureau education questions: Recommendations for researchers." Journal of Business and Economic Statistics 15, no. 3 (July): 300-309.

Jones, Benjamin F. 2014. "The human capital stock: A generalized approach." American Economic Review 104, no. 11: 3752-77.

Jovanovic, Boyan. 1979. "Job matching and the theory of turnover." Journal of Political Economy 87, no. 5 (October): 972-990.

Kaarsen, Nicolai. 2014. "Cross-country differences in the quality of schooling." Journal of Development Economics 107: 215-224.

Kaestner, Robert, and Ofer Malamud. 2014. "Self-selection and international migration: New evidence from Mexico." Review of Economics and Statistics 96, no. 1 (March): 78-91.

Klenow, Peter J., and Andres Rodriquez-Clare. 1997. "The neoclassical revival in growth economics: Has it gone too far?" In NBER Macroeconomics Annual 1997, edited by Ben S. Bernancke and Julio J. Rotemberg. Cambridge, MA: MIT Press: 83-103.

Lazear, Edward P. 2003. "Teacher incentives." Swedish Economic Policy Review 10, no. 3: 179214.

Lucas, Robert E., Jr. 1988. "On the mechanics of economic development." Journal of Monetary Economics 22, no. 1 (July): 3-42.

Mankiw, N. Gregory, David Romer, and David Weil. 1992. "A contribution to the empirics of economic growth." Quarterly Journal of Economics 107, no. 2 (May): 407-437.

Manuelli, Rodolfo E., and Ananth Seshadri. 2014. "Human capital and the wealth of nations." American Economic Review 104, no. 9: 2736-62.

McKenzie, David, John Gibson, and Steven Stillman. 2010. "How important is selection? Experimental vs. non-experimental measures of the income gains from migration." Journal of the European Economic Association 8, no. 4 (June): 913-945.

Mulligan, Casey B. 1999. "Galton versus the human capital approach to inheritance." Journal of Political Economy 107, no. 6, pt. 2 (December): S184-S224.

Murnane, Richard J., John B. Willett, Yves Duhaldeborde, and John H. Tyler. 2000. "How important are the cognitive skills of teenagers in predicting subsequent earnings?" Journal of Policy Analysis and Management 19, no. 4 (Fall): 547-568.

Murnane, Richard J., John B. Willett, and Frank Levy. 1995. "The growing importance of cognitive skills in wage determination." Review of Economics and Statistics 77, no. 2 (May): 251-266. 
National Center for Education Statistics. 2014. National Assessment of Educational Progress (NAEP). http://nces.ed.gov/nationsreportcard/naepdata/.

Neal, Derek, and William R. Johnson. 1996. "The role of pre-market factors in black-white differences." Journal of Political Economy 104, no. 5 (October): 869-895.

Nelson, Richard R., and Edmund Phelps. 1966. "Investment in humans, technology diffusion and economic growth." American Economic Review 56, no. 2 (May): 69-75.

Ortega, Francesc, and Giovanni Peri. 2013. "The effect of income and immigration policies on international migration." Migration Studies 1, no. 1 (March): 47-74.

Peri, Giovanni. 2012. "The effect of immigration on productivity: Evidence from U.S. states." Review of Economics and Statistics 94, no. 1 (February): 348-358.

Rappaport, Jordan, and Jeffrey D. Sachs. 2003. "The United States as a coastal nation." Journal of Economic Growth 8, no. 1: 5-46.

Romer, Paul. 1990. "Endogenous technological change." Journal of Political Economy 99, no. 5, pt. II: S71-S102.

Ruggles, Steven, J. Trent Alexander, Katie Genadek, Ronald Goeken, Matthew B. Schroeder, and Matthew Sobek. 2010. "Integrated Public Use Microdata Series: Version 5.0 [Machinereadable database]. University of Minnesota.

Schoellman, Todd. 2012. "Education quality and development accounting." Review of Economic Studies 79, no. 1 (January): 388-417.

Turner, Chad, Robert Tamura, and Sean E. Mulholland. 2013. "How important are human capital, physical capital and total factor productivity for determining state economic growth in the United States, 1840-2000?" Journal of Economic Growth 18, no. 4 (December): 319371.

Turner, Chad, Robert Tamura, Sean E. Mulholland, and Scott Baier. 2007. "Education and income of the states of the United States: 1840-2000." Journal of Economic Growth 12, no. 2 (June): 101-158.

U.S. Department of Education. 2013. Digest of Education Statistics, 2012. Washington, DC: National Center for Education Statistics. 


\section{Appendix A: Construction of Years of Schooling Measures by State}

We compile average years of educational attainment for each U.S. state from the Integrated Public Use Microdata Series (IPUMS) data of the Minnesota Population Center (Ruggles et al. (2010)). We concentrate on the working-age population between 20 and 65 years. We also drop all respondents who are still in school at the time of the survey.

For the years 1970 to 2000, we use the 1 percent (1970) and 5 percent $(1980,1990$, and 2000) random samples of the American population. The 1 percent sample has about 4 million observations, the 5 percent samples have about 13 to 14 million observations. Beginning in the year 2001, we use census data from the American Community Survey (ACS). The ACS provides annual 1 percent random population samples (with smaller sample sizes between 2001 and 2004). The approximate sample size is 3 million observations each year. Survey weights in the census and the ACS allow us to calculate measures that are representative for the U.S. population.

Until 1980, the Census reported directly the years of schooling or highest grade level completed of each individual. Beginning with the 1990 Census, the Census Bureau has changed the coding of educational categories and reports degrees (Bachelor, Master, etc.) instead. To translate the degree information into years of schooling, we use the estimates of average years of schooling of each degree provided by Jaeger (1997). ${ }^{29}$

Substantial differences in the labor-market performance between GED holders and standard high school graduates (Heckman, Humphries, and Mader (2011)) warrant a special treatment of GED holders. Due to the weak labor-market position of GED holders, we assign them 10 rather than 12 years of schooling.

Only the most recent survey waves identify GED holders in the Census data. We therefore estimate a constant share of GED holders among all high-school graduates from the pooled ACS 2008-2010 samples. The pooled sample is restricted for each year to get approximately the same age cohort of people aged 20-65. For example, for the year 2007, we use all people aged 21-66 in ACS 2008, 22-67 in ACS 2009, and 23-68 in 2010; for the year 1990, we use all people aged 3883 in ACS 2008, 39-84 in ACS 2009, and 40-85 in ACS 2010. Note that 1940 is not adjusted because the GED was introduced in 1942.

\footnotetext{
${ }^{29}$ Some Census years only report educational categories that cover several years of schooling. For these years, we assume the same fraction for this educational category as in the closest survey with full information.
} 
Overall, the GED adjustment affects the average years of schooling only very little, though. In 2007, for example, 15 percent of those who would have received 12 years of schooling otherwise are now assigned 10 years of schooling, reducing the mean of the average years of schooling from 12.33 to 12.27 years. Put differently, accounting for GED holders raises the mean share of those with less than 12 years of schooling from 22.6 percent to 26.7 percent.

Having computed the years of schooling of each individual $i$, the average years of schooling $S$ in state $s$ at time $t$ is then given by combining individual years of schooling by the weighted share of individuals $i$ with education level $e$ in the state at the time:

$$
S_{s t}=\sum_{e} \frac{\sum_{i} \text { person } \text { weights }_{\text {iest }}}{\sum_{i} \text { person weights } \text { ist }_{\text {is }}} * \text { years of schooling }{ }_{e}
$$

This yields the average years of schooling by state over time as shown in Figure 2.

\section{Appendix B: Construction of Test Score Measures by State}

As indicated in section 2.3 of the main text, our construction of cognitive skill measures for each U.S. state proceeds in four steps. This appendix provides methodological details on each step. First, we construct a constant measure of the mean test scores of students of each state (Appendix B.1). Second, we adjust the test scores of the working-age population of each state for interstate migration, thereby placing particular emphasis on the fact that interstate migration is selective (Appendix B.2). Third, test scores are adjusted for immigration from other countries, again with a special focus on selectivity (Appendix B.3). Fourth, we project test scores backward in time to allow for age-varying test scores in each state (Appendix B.4).

\section{B.1 Construction of Mean State Test Scores}

The National Assessment of Educational Progress (NAEP) studies the educational achievement of American students in grades four and eight in different subjects (National Center for Education Statistics (2014)). In our main analysis, we focus on the mathematics score in grade eight, on which we focus the following description. But as far as possible, we also computed test scores based on reading and grade four, as well as on a combination of subjects and grades.

Since 1990, NAEP math tests have been administered on a representative scale at the state level every two to four years for most states. By 2003, test scores are available for all states. 


\section{Adjustment of Pre-1996 Tests for Accommodation}

Since 1996, NAEP allows students with disabilities and English language learners specific accommodations to facilitate test participation. The NAEP test scores before 1996 (in 1990 and 1992) did not permit such accommodation, so that they have to be adjusted in order to be on a common scale with the subsequent tests. Therefore, we rescale the pre-1996 tests as follows: For 1996, NAEP test scores and standard deviations are available for tests with and without accommodation at the national level. By subtracting the 1996 U.S. mean without accommodation from the state score and dividing by the 1996 U.S. standard deviation without accommodation, we standardize test scores to mean 0 and standard deviation of 1. By multiplying the 1996 U.S. standard deviation with accommodation and adding the 1996 U.S. mean with accommodation, we bring each test score before 1996 to the same scale as the tests that permitted accommodation.

That is, the pre-1996 waves are aligned to the post-1996 scale in the following way:

$$
\operatorname{score}_{s t}^{a d j}=\left(\frac{\text { score }_{s t}-\text { mean }_{U S, t=1996}^{\text {same scale }}}{s d_{U S, t=1996}^{\text {same scale }}}\right) * s d_{U S, t=1996}^{\text {new scale }}+\text { mean }_{U S, t=1996}^{\text {new scale }}
$$

where score $_{s t}$ is the raw score (without accommodation) of state $s$ at time $t$, mean refers to the U.S. national mean, sd refers to the U.S. standard deviation, same scale refers to scores without accommodation, and new scale refers to scores with accommodation.

\section{Normalization of Scales to Base Year 2011}

Next, we normalize each scale - eight-grade math, etc. - to have a mean of 500 and a standard deviation of 100 in the common base year 2011. This is done by subtracting from each test score the 2011 U.S. mean and dividing by the 2011 U.S. standard deviation and then multiplying by 100 and adding 500:

$$
\text { score }_{S t}^{\text {standard }}=\left(\frac{\text { score }_{S t}^{\text {adj }}-\text { mean }_{U S, t=2011}}{s d_{U S, t=2011}}\right) * 100+500
$$

\section{Regression-based Estimation of Mean State Scores by State Fixed Effects}

Using the normalized scores, we estimate the average test score of each state over all test scores that are available until 2011. This is done by estimating state fixed effects in a regression 
with year fixed effects that take into account systematic differences over time, as well as - in estimations that combine tests across subjects and grades - grade-by-subject fixed effects that takes into account systematic differences between grades and subjects:

$$
\text { score }_{\text {sgut }}^{\text {standard }}=\sum_{s=1}^{50} \alpha_{s} I_{s}+I_{g} * I_{u}+I_{t}+\epsilon_{\text {sgut }}
$$

$I_{s}$ is the fixed effect of state $s$ that we are interested in. $I_{t}$ are time fixed effects and $I_{g} * I_{u}$ are grade-by-subject fixed effects. By leaving out the indicators that represent math, grade eight, and the year 2011, all state fixed effects refer to this subject, grade, and year. The same adjustments and estimations can also be performed for different subsamples of the population, e.g., by education category of the parents.

\section{B.2 Adjustment for Interstate Migration}

\section{Adjusting for State of Birth}

To be able to adjust the state skill measure for interstate migration, we start by computing the birthplace composition of each state from the Census data. In particular, we compute the population shares of people currently living in state $s$ who were born in state $s$ ("state locals"), those born in in another state $k$ (“interstate migrants"), and those born in another country (“international immigrants”). Thus, the population share of individuals $i$ from origin state/country $o$ living in state $s$ at time $t$ is given by

$$
\text { population share } \text { ost }=\frac{\sum_{i} \text { person } \text { weights }_{\text {iost }}}{\sum_{i} \text { person } \text { weights }_{\text {ist }}}
$$

Each state is composed of individuals educated in other states. To adjust, at least partially, for the differences in schooling that these individuals brought with them to their current state of residence, we construct a series of composite test scores. The idea is that each person who is living in a state receives the test score of his home state. The baseline composite test score of state $s$ at time $t$ is then the weighted sum of test scores from all origin states $o$ which are weighted by the fraction of people born in a particular origin $o$ living in state $s$ at time $t$ :

$$
\text { score }_{\text {st }}^{\text {adj }}=\sum_{o} \text { population share } \text { ost } \times \text { score }_{o}
$$

Thus, each person currently living in a state is assigned the test score from the respective state of birth. 
The baseline composite test score thus assigns all locals the mean test score of the state of residence which is also their state of birth, assuming that the locals have not moved during their school career to another state. Assuming that internal migrants have not left their state of birth before finishing grade eight, all internal migrants receive the mean test score of their state of birth. In this variant, the international immigrants receive the mean score of their current state of residence.

\section{Adjusting for Selective Interstate Migration based on Educational Background}

To address selective interstate migration, we compute all population shares separately by educational background. We distinguish two educational categories: Persons with (at least some) university education and persons without university education. For each state, we also construct separate test scores by the education category of the parents (some university education or not).

We then assign separate test scores by educational background $e$ :

$$
\text { score }_{\text {st }}^{\text {sel }}=\sum_{o e} \text { population share } \text { oest } \times \text { score }_{o e}
$$

For state locals, this adjusted score replaces the average test score of the state of residence with the average test score of the state of residence by education category (university / no university). Likewise, for in-migrants it adjusts the average test scores of by education category. The assumption is that we can assign the population with a university education the test score of children with parents who have a university degree, and equivalently for those without a university education.

\section{B.3 Adjustment for International Migration}

Our adjustment for international migration combines data from international achievement tests with population shares of immigrants from different countries of origin.

\section{International Test Score Data}

We use international test score data from PISA, TIMSS, and PIRLS for international immigrants residing in one of the U.S. states. ${ }^{30}$ As a first step, the international test data have to be rescaled onto a common scale with the national NAEP data (Hanushek, Peterson, and

\footnotetext{
${ }^{30}$ We draw the data from the International Data Explorer (IDE) of the National Center of Education Statistics (http://nces.ed.gov/surveys/international/ide/).
} 
Woessmann (2012)). To do so, we first standardize all international test scores by subtracting from each mean score on the international scale the U.S. mean value on the international scale by subject, grade, and year and divide this difference by the U.S. standard deviation on the international scale, also by subject, grade, and year. Next, we multiply the standardized value by the U.S. standard deviation of the NAEP score by subject, grade, and year and add the U.S. mean of the NAEP score by subject, grade, and year:

$$
\operatorname{score}_{s g u t}^{\text {adj }}=\left(\frac{\text { score }_{s g u t}-m e a n_{U S, g u t}^{i n t^{\prime} l}}{s d_{U S, g u t}^{\text {int }}}\right) * s d_{U S, g u t}^{N A E P}+\operatorname{mean}_{U S, g u t}^{N A E P}
$$

where score $_{\text {sgut }}$ is the raw international test score of country $s$ at grade $g$ in subject $u$ in year $t$.

To compute average test scores for each country, we proceed in the same way as for the national test data. The regression design takes into account systematic differences between grades, subjects, and years. The final estimate of the country average test score is then a country fixed effect:

$$
\text { score }_{\text {sgut }}^{\text {standard }}=\sum_{s} \alpha_{s} I_{s}+I_{g} * I_{u} * I_{\text {test }}+I_{t}+\epsilon_{\text {sgut }}
$$

where $I_{s}$ is the fixed effect of country $s$ that we are interested in. $I_{t}$ are time fixed effects and $I_{g} * I_{u} * I_{\text {test }}$ are grade times subject times survey fixed effects. The survey fixed effects indicate whether we identify grade 4 in PIRLS or grade 4 in TIMSS. Thus, they are dummy variables for TIMSS, PIRLS, and PISA. Again, the same regression can be estimated for different subsamples of the population. ${ }^{31}$

Apart from the mean test score, we also estimate the performance of the $75^{\text {th }}$ and the $90^{\text {th }}$ percentile of students in each country.

In cases where a source country did not participate in the international achievement tests, we impute values from neighboring countries or regions. Table A3 reports the respective imputations for the main source countries of immigrants in the United States.

\footnotetext{
${ }^{31}$ When estimating separate scores by the education category of the father, in PISA we use a simple average of the test scores in ISCED categories 0-4 for non-university education and ISCED categories 5a and 6 for university education. In TIMSS 1995 and 1999, we use the average of the categories until "finished secondary" for nonuniversity education and "finished university" for university education. In the subsequent TIMSS waves, we use ISCED categories 0-4 for non-university education and ISCED categories 5a and more than 5a for university education. The IDE does not report educational background variables for PIRLS and TIMSS grade 4.
} 


\section{Population Shares of Immigrants from Different Countries of Origin}

Using Census data, we next calculate the population shares of those born outside U.S. Table A3 shows the main source countries of immigrants who came to the United States over the last 70 years.

In calculating the share of immigrants from different origin countries in the birthplace composition of each state, we take into account the age of immigration. In particular, immigrants arriving in the United States before the age of 6 are assumed to have spent their school career in the U.S. school system, so they are assigned the NAEP score of their state of residence. Those who immigrated after the age of 20 are assigned the test score of their country of origin. And those who immigrated between ages 6 and 20 are assigned a weighted average of the two.

Using the population shares of immigrants from different countries of origin as in equation (B4), we then basically proceed in the same way as with the national test score data. That is, we adjust the composite test score of each state by applying the country-of-origin test scores for international immigrants. In a first variant, we assign the average test score by country of origin and education category as in equation (B6). In a second and third variant, we account for selectivity in the international migration by assigning the $75^{\text {th }}$ and the $90^{\text {th }}$ percentile, respectively, of the skill distribution in the country of origin, assuming that immigrants are positively selected from the source country population and much more skilled than those left behind.

\section{B.4 Backward Projection of Time-Varying Scores}

Finally, we employ two methods of age projections of historical achievement patterns, one based on extrapolation from the available NAEP data and one based on projection from state SAT scores.

\section{Extrapolation of NAEP Trends}

The skill measures developed so far assume that an average test score applies to the whole working-age population. We now aim to project developments of cognitive skills over time by state. Because test score data are not available before 1990 at the state level, we project test scores back in time, incorporating the long-term national trend which dates back to 1978 for eighth-grade math. For the projections, we do not use the 1990 value but rather start in 1992, as 
the very first test scores seem to differ somewhat from the subsequent trends. The basic idea of our backward projection is to use an average of the linear trend in the state test score and the observed national trend to predict the test score of the state in a given year until 1978, i.e. from 1978 to 1992.

The national NAEP series that goes back until 1978, called long-term trend NAEP, is on a slightly different scale than the state NAEP series used in the state analysis. First, as scores reported prior to 2004 are reported in a different testing format and both formats are reported for 2004, we align the prior scores by standardization equivalent to the adjustment for scores without accommodation above. Then, to make the scales comparable, we subtract from each long-term trend test score the long-term trend score in 1992 and divide by the U.S. standard deviation in 1992 from the long-term trend. We then multiply this term by the U.S. standard deviation in 1992 from the state NAEP series and add the national mean from the from the state NAEP series.

We start the projection by interpolating the available test scores linearly for each state from 1992 to $2011 .^{32}$ The projection then follows an iterative process: We assume that each test score of state $s$ in $t-1, \widetilde{T}_{s, t-1}$, is equal to the test score in $t, T_{s t}$, minus a simple average of the change in the state-specific linear time trend, i.e. the slope of the time trend, and the change in the national time trend:

$$
\tilde{T}_{s, t-1}=T_{s t}-\frac{1}{2}\left(x_{t} \Delta \text { Linear State } \text { Trend }_{s t}+\Delta \overline{\text { Natıonal }_{t}}\right)
$$

where

$$
\begin{gathered}
\Delta \text { Linear State Trend }_{s t}=\text { Linear State Trend } \\
\text { st } \\
\qquad \overline{\text { Natlonal }_{t}}=\overline{\text { Natlonal }_{t}}-\overline{\text { Natlonal }_{t-1}}
\end{gathered}
$$

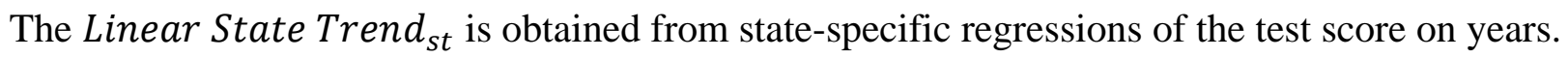
$\overline{\text { Natlonal }_{t}}$ is the long-term trend national average and available backwards until 1978.

To ensure that the (weighted) average of all state test scores is equal to the national average, we adjust the linear state trend with a time-varying constant, $x_{t}$. This adjustment factor is

\footnotetext{
${ }^{32}$ A few states started representative NAEP testing later than 1992. These are Alaska, Montana, Oregon, Vermont, and Washington in 1996, Illinois, Kansas, and Nevada in 2000, and South Dakota in 2003. We project their scores back to 1992 with a simple backward projection method: $\tilde{T}_{s, t-1}=T_{s t}-\frac{1}{2}\left(\Delta\right.$ Linear State Trend $d_{s t}+$ $\Delta \overline{\text { Natıonal }}$ ).
} 
computed by taking the weighted sum of the test score projection on both sides and solving for $x_{t}$ :

$$
\begin{aligned}
& \overline{\text { Natlonal }_{t-1}}=\sum_{s=1}^{51} w_{s} \widetilde{T}_{s, t-1}, \text { for } t \leq 1991 \text { and } \sum_{s=1}^{51} w_{s}=1 \\
& \Leftrightarrow x_{t}=\frac{2 * \sum_{s=1}^{51} w_{s} T_{s t}-\overline{\text { Natlonal }_{t}}-\overline{\text { Natlonal }_{t-1}}}{\sum_{s=1}^{51} w_{s} \Delta \text { Linear State }_{\text {Trend }} \text { st }}
\end{aligned}
$$

The weights, $w_{s}$, are based on average daily attendance in public elementary and secondary schools by state from the Digest of Education Statistics (U.S. Department of Education (2013)). To obtain a weight for each state, we divide the average daily attendance in the state by the total national daily attendance. This measure is averaged over the time period 1978 to 1992 as the fractions are rather stable. The cross-sectional correlation between the fractions in 1978 and in 1992 is 98 percent.

The projected test score series then uses the available test score information for each state from 1992 to 2011 and the projected scores from the above iterative procedure from 1978 to 1992. Before 1978, we either assume a constant test score or a linear state trend.

The adjusted skill measure is then constructed by taking five-year averages of the projected test score series. These five year averages are then matched to the population shares of the appropriate age. To match the projected test score data, the share of people from origin $o$ living in state $s$ in equation (B4) is computed in five-year age intervals from the Census data, both for the state average and for the education-category subsamples. The adjusted skill measure is then derived as

$$
\text { score }_{\text {st }}^{\text {projected }}=\sum_{\text {oea }} \text { population share } \text { oeast } \times \text { score }_{\text {oea }}
$$

where the population shares and scores now do not only vary by state of origin $o$ and educational category $e$, but also by age category $a$.

\section{Projection from State SAT Scores}

We obtained state-specific SAT scores (in math, writing, and reading) from 1972 to 2013 from the College Board. SAT scores are not representative for the total student population. But College Board also provided information on total participation (number of test takers). We calculate SAT participation rates by dividing the number of SAT participants by the total number 
of public high school graduates in each state. The latter is collected from various years of the Digest of Education Statistics (filling gaps by linear interpolation between available years).

Regressing the SAT score on the participation rate shows a significant negative relationship, indicating that a higher participation rate is related to a less selective sample and lower test scores. We therefore construct a series of participation-adjusted SAT scores:

$$
\text { SAT } \text { score }_{s t}=\alpha_{0}+\alpha_{1} \text { participation rate } \text { st }+\lambda_{s}+\lambda_{t}+\epsilon_{s t}
$$

We use the estimated coefficients to predict SAT test scores with constant participation rates, where we assume that all states have the mean U.S. participation rate over the period 1972 to 2013 of 46.9 percent.

The participation-adjusted SAT scores allow us to predict state NAEP scores before 1992. To do so, we first regress the eighth-grade math test scores in NAEP on the participationadjusted SAT scores by state for the years since 1992 where both test scores series are available:

$$
N A E P \text { score }_{t}=\beta_{0}+\beta_{1} S A T \text { score } e_{t}^{\text {adjusted }}+\epsilon_{t}
$$

Because the SAT is taken around high school graduation, in these regressions we lag the SAT test scores by four years to capture almost the same cohorts as in NAEP. The regressions show that the participation-adjusted SAT score and the NAEP score move together over time in almost all states. $^{33}$

With the estimated coefficients, we can then construct predicted NAEP test scores for each state for the years 1968 to 1991. Applying the same algorithm for the projection of test scores by age as before, we construct new aggregate test scores for each state and year by using the predicted NAEP test scores based on the SAT data.

\footnotetext{
33 Exceptions are Kansas, Nevada, and South Dakota, which are also the states that start relatively late in NAEP, thereby impeding the prediction of a reliable connection between NAEP and SAT. For these states, we use the U.S. average coefficient.
} 
Figure 1: Distribution of GDP per Capita of U.S. States, 1970-2007

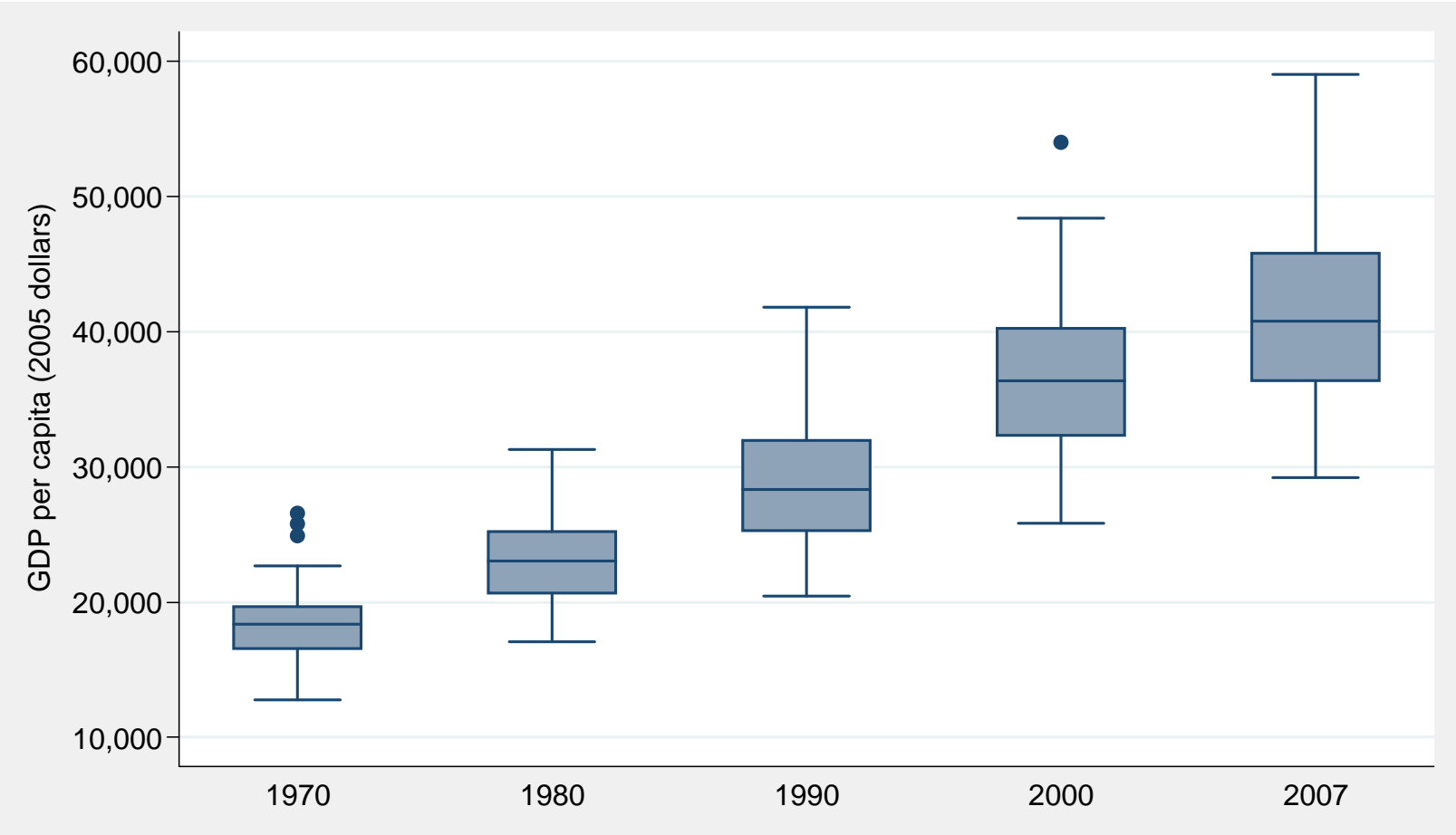

Notes: GDP per capita denoted in 2005 U.S. dollars. Boxplots of 47 U.S. states (Alaska, Delaware, and Wyoming excluded). Boxplot description: The line in the middle of each box depicts the median state. The bottom and top of each box indicate the states at the $25^{\text {th }}$ and $75^{\text {th }}$ percentiles, respectively. Dots indicate large outliers outside of the normal data range. Source: Authors' calculations based on data from Bureau of Economic Analysis (2013a, 2013b, 2013c). 
Figure 2: Distribution of Average Years of Schooling of U.S. States, 1970-2007

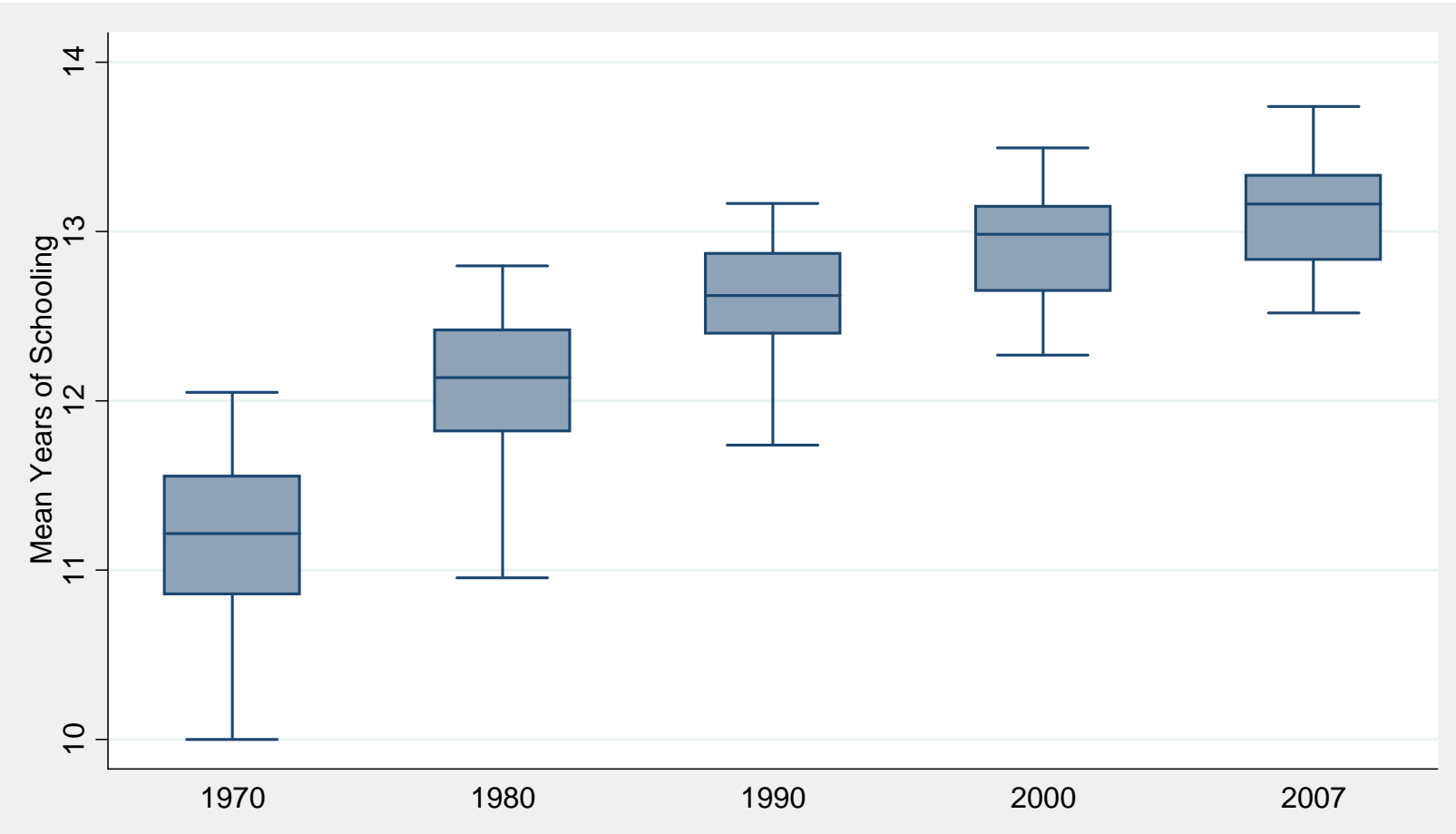

Notes: See Figure 1 for sample and boxplot description. Source: Authors' calculations based on data from Ruggles et al. (2010). 
Figure 3: Share of State Locals in the Population of U.S. States, 1970-2007

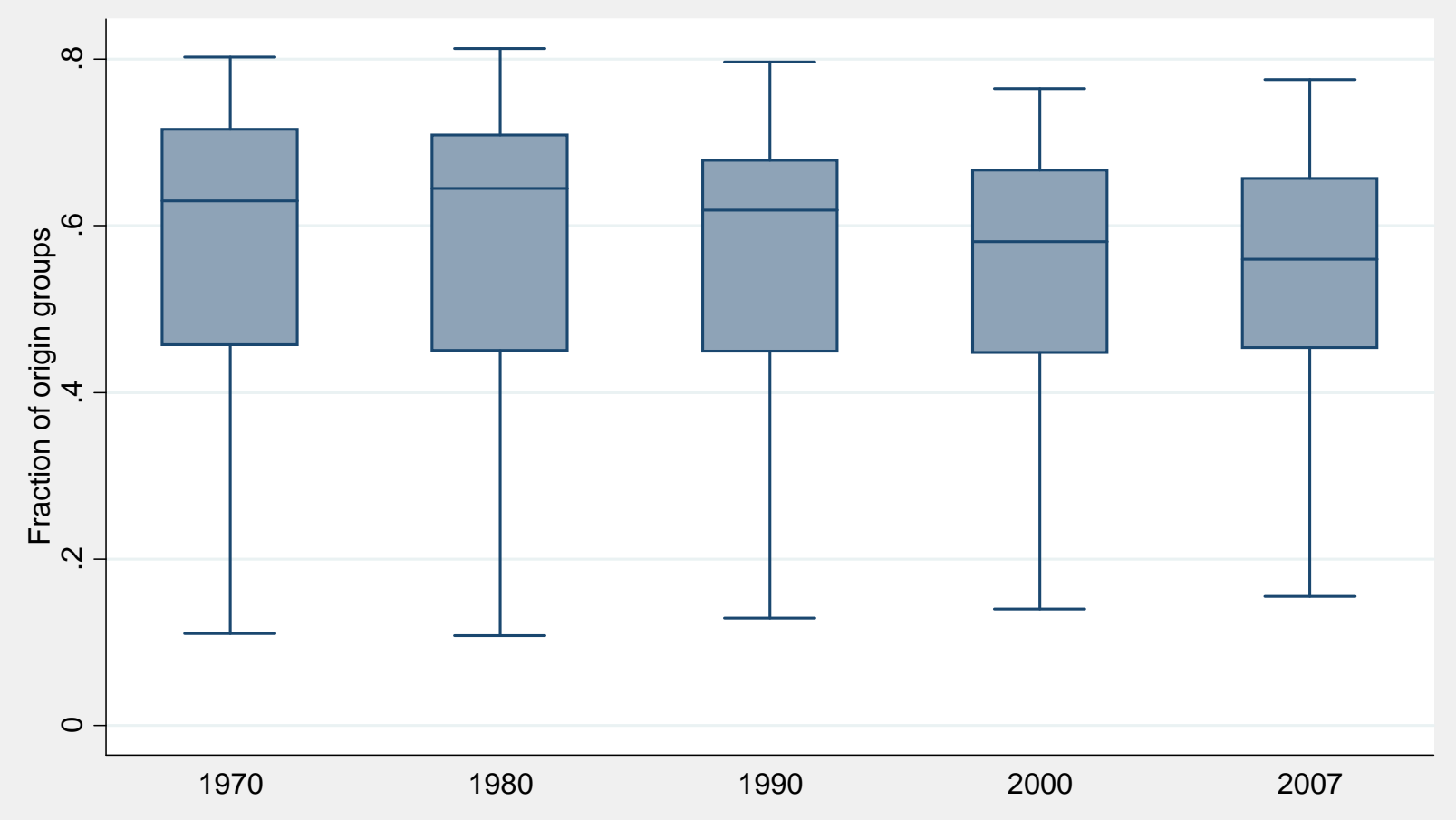

Notes: Fraction of people with state of birth equal to current state. See Figure 1 for sample and boxplot description. Source: Authors' calculations based on data from Ruggles et al. (2010). 
Figure 4: Average Math Test Scores of U.S. States by Educational Background

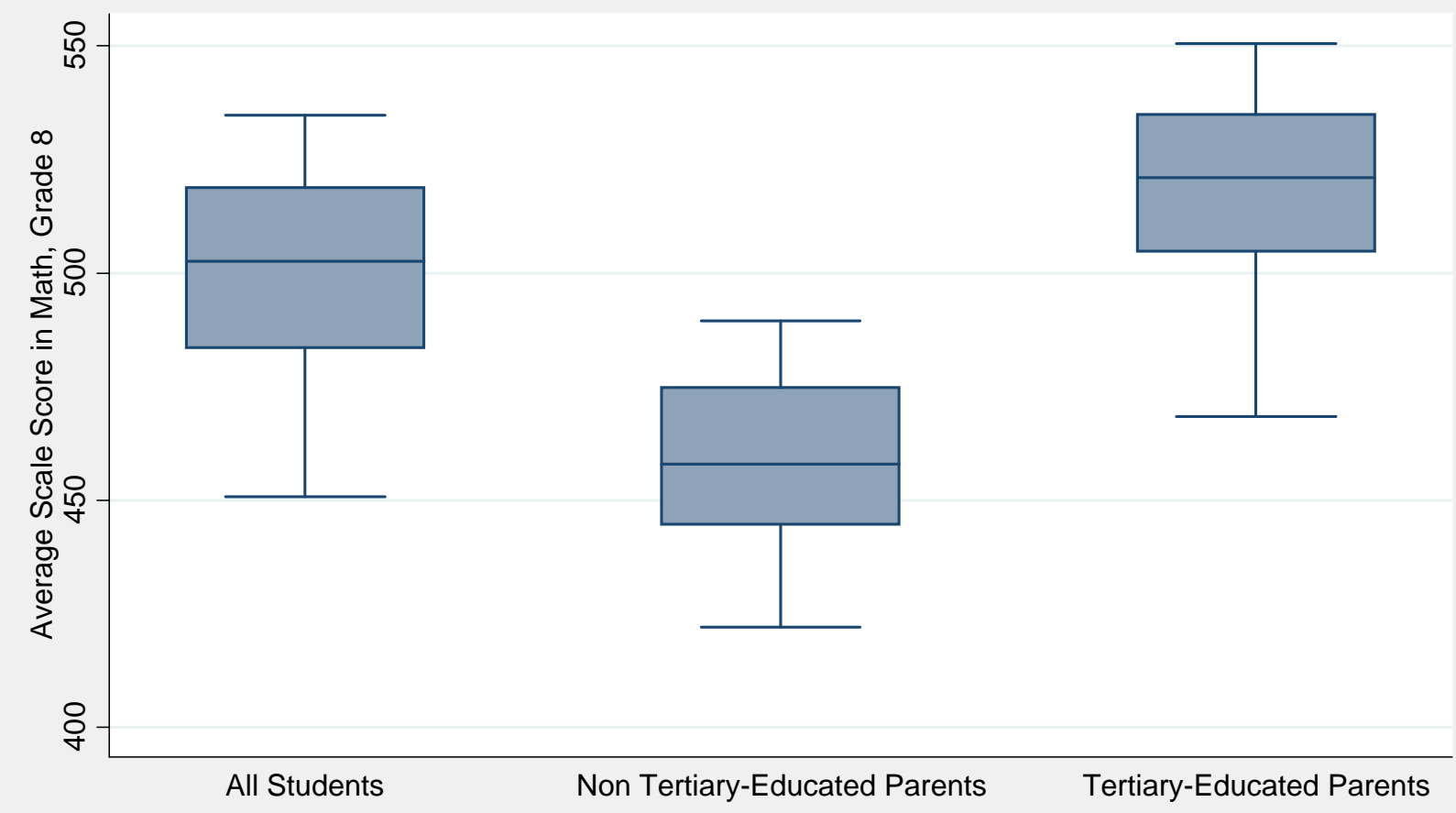

Notes: NAEP test score in eighth-grade math, 1990-2011. See Figure 1 for boxplot description. Source: Authors' calculations based on data from National Center for Education Statistics (2014). 
Figure 5: Share of U.S.-Born People in the Population of U.S. States, 1970-2007

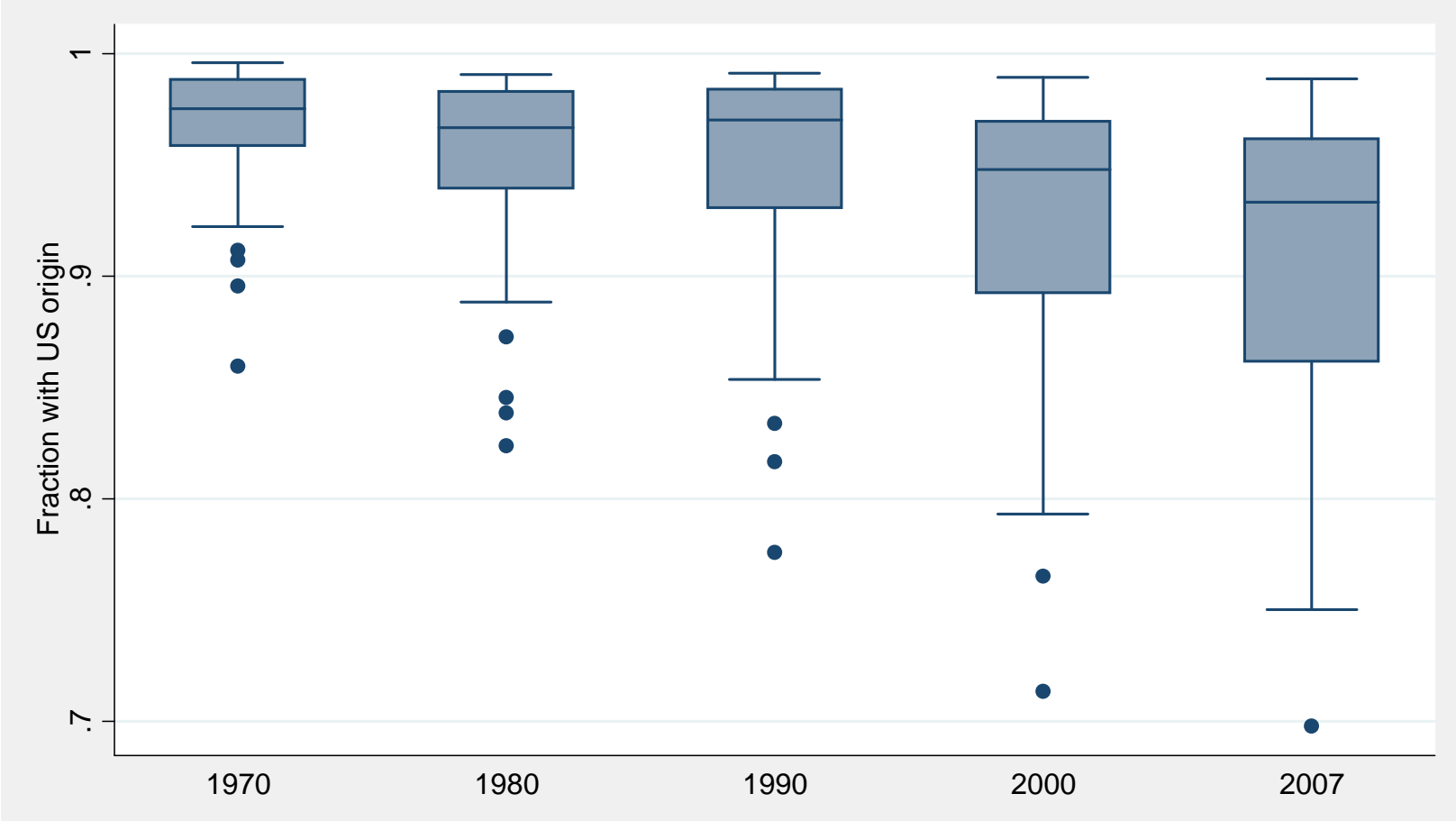

Notes: See Figure 1 for sample and boxplot description. Source: Authors' calculations based on data from Ruggles et al. (2010). 
Figure 6: Projection of Test Scores for Massachusetts and Mississippi

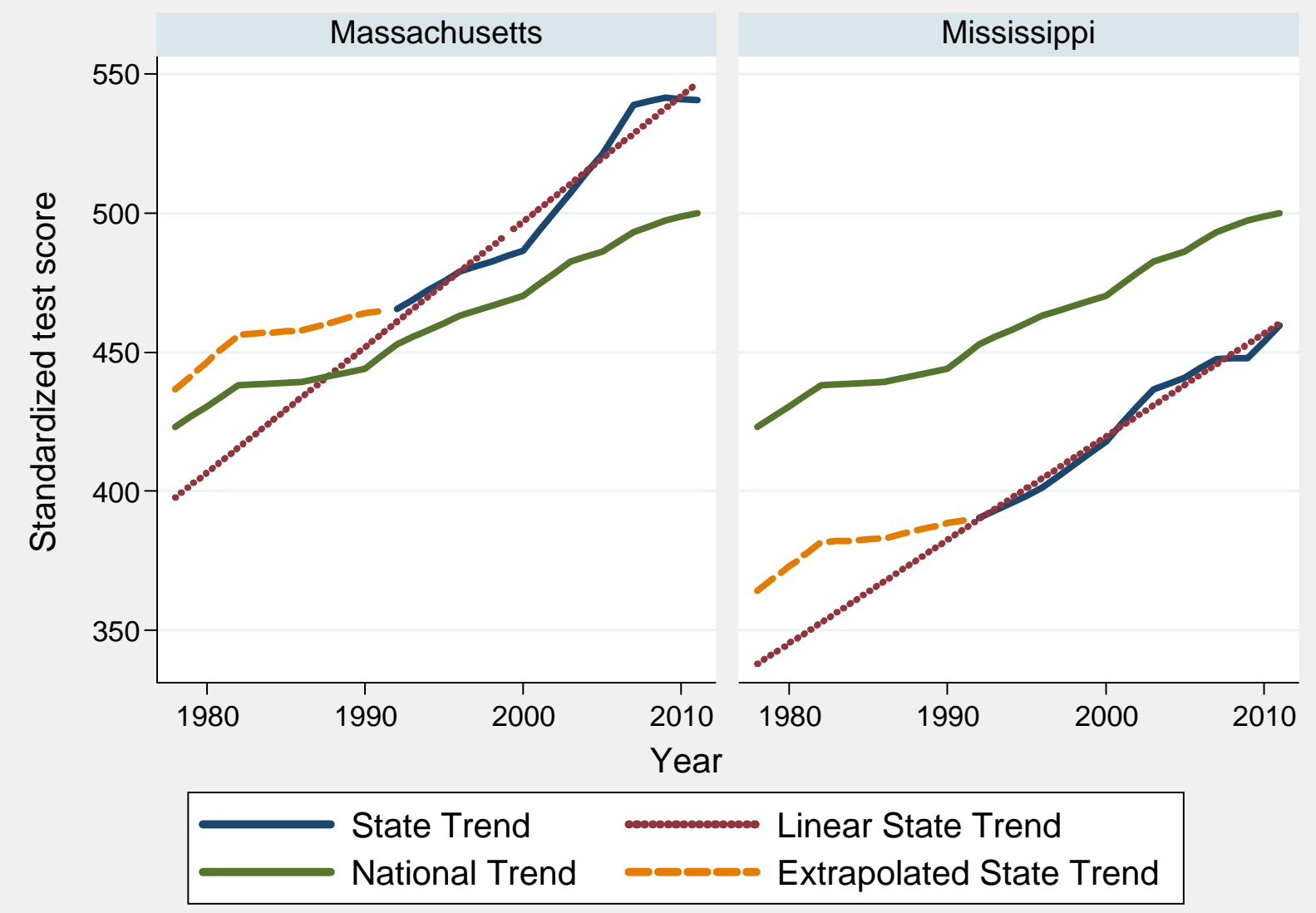

Notes: NAEP test score in eighth-grade math. Source: Authors' calculations based on data from National Center for Education Statistics (2014). 
Figure 7: Years of Schooling and GDP per Capita across U.S. States, 2007

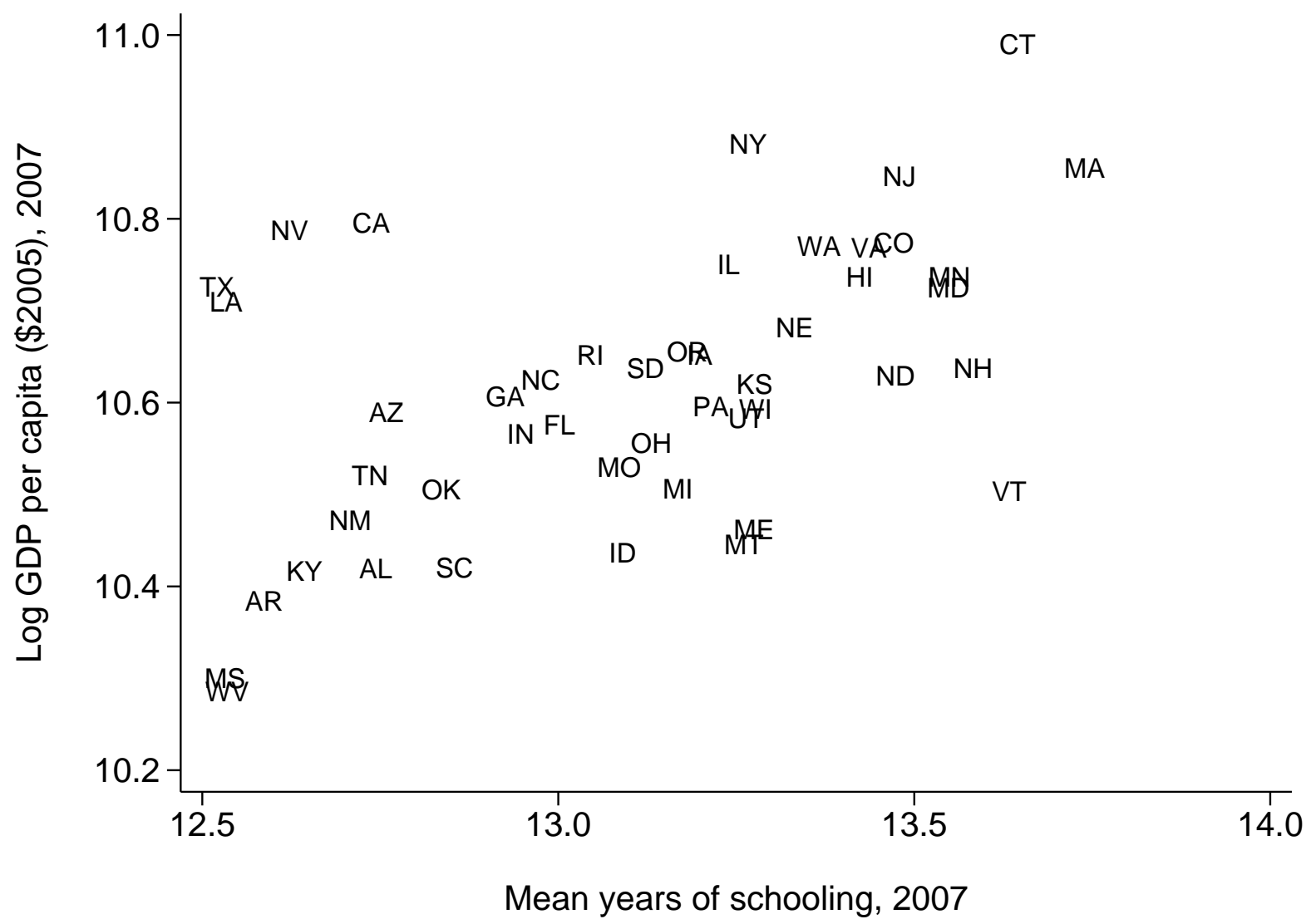

Notes: Scatterplot of average years of schooling of the working-age population and log real GDP per capita across U.S. states, 2007. Source: Authors' calculations based on data from Bureau of Economic Analysis (2013a, 2013b, 2013c) and Ruggles et al. (2010). 
Figure 8: Cognitive Skills and GDP per Capita across U.S. States, 2007

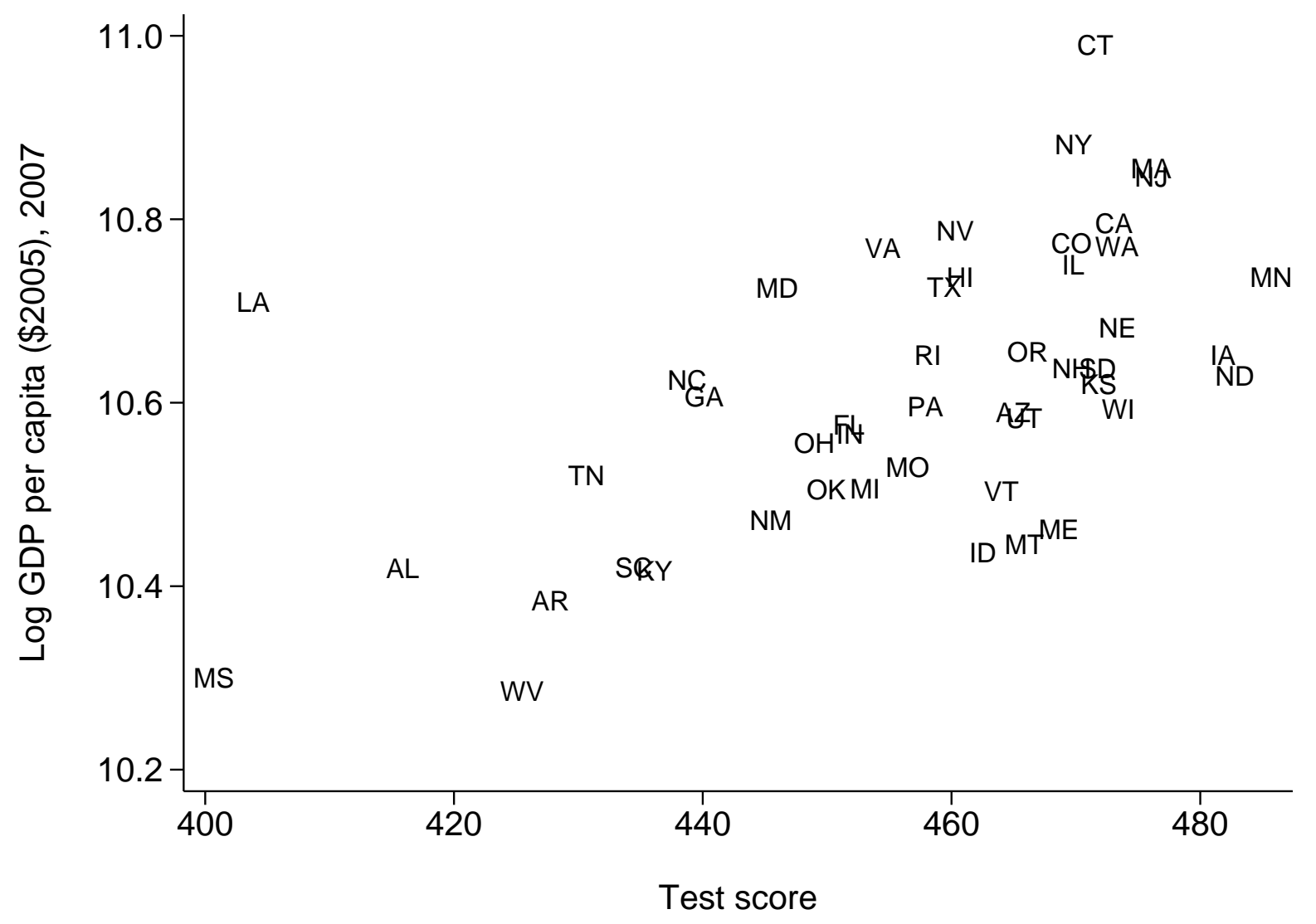

Notes: Scatterplot of cognitive skill measure (adjusted for selective interstate migration and for international migration by the $90^{\text {th }}$ percentile) and log real GDP per capita across U.S. states, 2007. Source: Authors' calculations based on data from Bureau of Economic Analysis (2013a, 2013b, 2013c), Ruggles et al. (2010), and National Center for Education Statistics (2014). 
Figure 9: Growth Accounting by State, 1970-2007

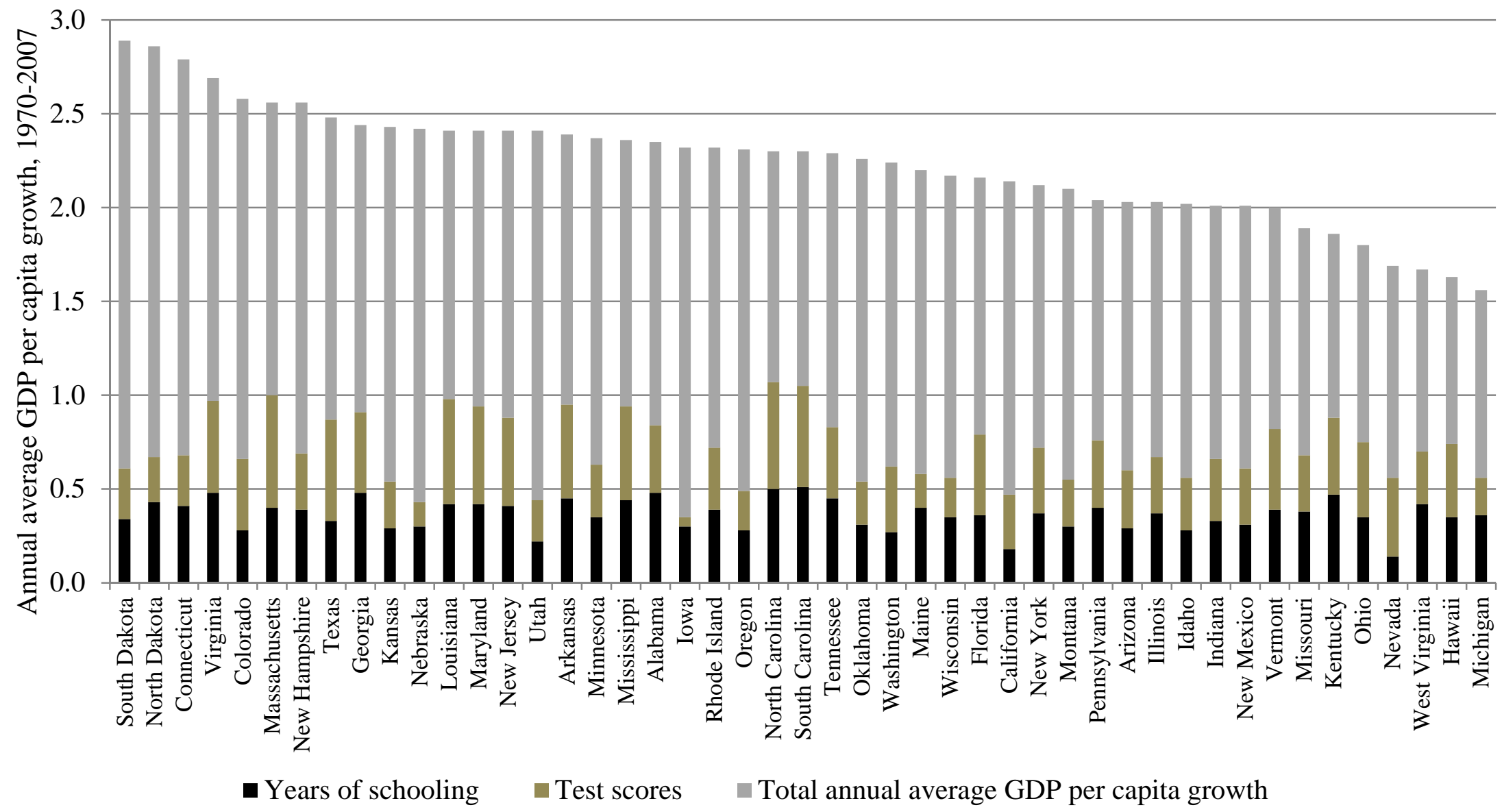

Notes: Growth accounting results by U.S. states. Contribution of changes in years of schooling and in estimated test scores to the average annual rate of growth in GDP per capita in 1970-2007. See Appendix Table A5 for details. Source: Authors' calculations based on data from Bureau of Economic Analysis (2013a, 2013b, 2013c), Ruggles et al. (2010), and National Center for Education Statistics (2014). 
Table 1: Correlations among Test Score Measures, 2007

\begin{tabular}{|c|c|c|c|c|c|c|c|c|c|}
\hline & Test score specification & 1 & 2 & 3 & 4 & 5 & 6 & 7 & 8 \\
\hline 1 & Baseline: local average adjusted for interstate migrants & 1 & & & & & & & \\
\hline 2 & + Adjustment of locals by education category & 0.990 & 1 & & & & & & \\
\hline \multirow[t]{2}{*}{3} & + Adjustment of interstate migrants by education category & 0.984 & 0.996 & 1 & & & & & \\
\hline & + Adjustment of international migrants: & & & & & & & & \\
\hline 4 & By education category in country of birth & 0.958 & 0.942 & 0.934 & 1 & & & & \\
\hline 5 & By $75^{\text {th }}$ percentile in country of birth & 0.968 & 0.979 & 0.980 & 0.971 & 1 & & & \\
\hline 6 & By $90^{\text {th }}$ percentile in country of birth & 0.904 & 0.945 & 0.959 & 0.851 & 0.952 & 1 & & \\
\hline 7 & Age adjustment with extrapolation of NAEP trends by education category & 0.781 & 0.833 & 0.846 & 0.730 & 0.851 & 0.928 & 1 & \\
\hline 8 & Age adjustment with projection from SAT scores & 0.645 & 0.685 & 0.688 & 0.606 & 0.703 & 0.759 & 0.914 & 1 \\
\hline
\end{tabular}

Notes: Test scores refer to eighth-grade math. Locals are all persons who report a state of birth equal to the current state of residence. Interstate migrants report another state of birth than state of residence. International migrants report another country of birth than the United States. "By education category" indicates that individuals with/without university education are assigned the test scores of children of parents with/without university education. 
Table 2: Development Accounting Results with Basic Test Score Specifications, 2007

\begin{tabular}{|c|c|c|c|c|c|c|}
\hline \multirow[b]{2}{*}{ Test score specification } & \multicolumn{3}{|c|}{ Covariance Measure } & \multicolumn{3}{|c|}{ Five-State Measure } \\
\hline & $\begin{array}{c}\text { Total } \\
\text { human capital }\end{array}$ & $\begin{array}{c}\text { Test } \\
\text { scores }\end{array}$ & $\begin{array}{c}\text { Years of } \\
\text { schooling }\end{array}$ & $\begin{array}{c}\text { Total } \\
\text { human capital }\end{array}$ & $\begin{array}{c}\text { Test } \\
\text { scores }\end{array}$ & $\begin{array}{l}\text { Years of } \\
\text { schooling }\end{array}$ \\
\hline Baseline: local average adjusted for interstate migrants & $\begin{array}{l}0.184^{* * *} \\
(0.054)\end{array}$ & $\begin{array}{l}0.067^{* *} \\
(0.030)\end{array}$ & $\begin{array}{l}0.117^{* * *} \\
(0.028)\end{array}$ & 0.259 & 0.109 & 0.149 \\
\hline + Adjustment of locals by education category & $\begin{array}{l}0.195^{* * *} \\
(0.052)\end{array}$ & $\begin{array}{l}0.078^{* * *} \\
(0.028)\end{array}$ & $\begin{array}{l}0.117^{* * *} \\
(0.028)\end{array}$ & 0.268 & 0.119 & 0.149 \\
\hline + Adjustment of interstate migrants by education category & $\begin{array}{l}0.206^{* * *} \\
(0.053)\end{array}$ & $\begin{array}{l}0.089^{* * *} \\
(0.028)\end{array}$ & $\begin{array}{l}0.117^{* * *} \\
(0.028)\end{array}$ & 0.280 & 0.131 & 0.149 \\
\hline \multicolumn{7}{|l|}{ + Adjustment of international migrants: } \\
\hline By education category in country of birth & $\begin{array}{l}0.154^{* * *} \\
(0.054)\end{array}$ & $\begin{array}{c}0.038 \\
(0.030)\end{array}$ & $\begin{array}{l}0.117^{* * *} \\
(0.028)\end{array}$ & 0.219 & 0.070 & 0.149 \\
\hline By $75^{\text {th }}$ percentile in country of birth & $\begin{array}{l}0.187^{* * *} \\
(0.051)\end{array}$ & $\begin{array}{l}0.070^{* *} \\
(0.027)\end{array}$ & $\begin{array}{l}0.117^{* * *} \\
(0.028)\end{array}$ & 0.257 & 0.108 & 0.149 \\
\hline By $90^{\text {th }}$ percentile in country of birth & $\begin{array}{l}0.229^{* * *} \\
(0.048)\end{array}$ & $\begin{array}{l}0.111^{* * *} \\
(0.025)\end{array}$ & $\begin{array}{l}0.117^{* * *} \\
(0.028)\end{array}$ & 0.305 & 0.156 & 0.149 \\
\hline
\end{tabular}

Notes: Development accounting results for 47 U.S. states with different test score specifications. Test scores refer to eighth-grade math. Locals are all persons who report a state of birth equal to the current state of residence. Interstate migrants report another state of birth than state of residence. International migrants report another country of birth than the United States. "By education category" indicates that individuals with/without university education are assigned the test scores of children of parents with/without university education. Calculations assume a return of $w=0.2$ per standard deviation in test scores and a return of $r=0.1$ per year of schooling. Bootstrapped standard errors in parentheses with 1,000 replications. Significance levels: ${ }^{*} \mathrm{p}<0.10,{ }^{* *} \mathrm{p}<0.05,{ }^{* * *} \mathrm{p}<0.01$. 
Table 3: Development Accounting Results for Different Years

\begin{tabular}{|c|c|c|c|c|c|c|c|}
\hline \multirow{2}{*}{$\begin{array}{l}\text { Test score specification } \\
\text { Baseline: local average adjusted for interstate migrants }\end{array}$} & \multirow{2}{*}{$\begin{array}{c}\text { Year } \\
2007\end{array}$} & \multicolumn{2}{|c|}{ Total human capital } & \multicolumn{2}{|c|}{ Test scores } & \multicolumn{2}{|c|}{ Years of schooling } \\
\hline & & $0.184^{* * *}$ & $(0.054)$ & $0.067^{* *}$ & $(0.030)$ & $0.117^{* * *}$ & $(0.028)$ \\
\hline & 2000 & $0.182^{* * *}$ & $(0.057)$ & $0.072^{* *}$ & $(0.030)$ & $0.110^{* * *}$ & $(0.030)$ \\
\hline & 1990 & $0.156^{* * *}$ & $(0.059)$ & 0.037 & $(0.034)$ & $0.120^{* * *}$ & $(0.029)$ \\
\hline & 1980 & $0.192^{* *}$ & $(0.095)$ & 0.028 & $(0.045)$ & $0.163^{* * *}$ & $(0.055)$ \\
\hline & 1970 & $0.222^{* * *}$ & $(0.073)$ & 0.033 & $(0.039)$ & $0.189^{* * *}$ & $(0.040)$ \\
\hline \multirow[t]{5}{*}{ + Adjustment of locals by education category } & 2007 & $0.195^{* * *}$ & $(0.052)$ & $0.078^{* * *}$ & $(0.028)$ & $0.117^{* * *}$ & $(0.028)$ \\
\hline & 2000 & $0.191^{* * *}$ & $(0.056)$ & $0.081^{* * *}$ & $(0.029)$ & $0.110^{* * *}$ & $(0.030)$ \\
\hline & 1990 & $0.169^{* * *}$ & $(0.056)$ & 0.049 & $(0.032)$ & $0.120^{* * *}$ & (0.029) \\
\hline & 1980 & $0.222^{* *}$ & $(0.093)$ & 0.058 & $(0.042)$ & $0.163^{* * *}$ & $(0.055)$ \\
\hline & 1970 & $0.244^{* * *}$ & $(0.072)$ & 0.055 & $(0.036)$ & $0.189^{* * *}$ & $(0.040)$ \\
\hline \multirow[t]{5}{*}{ + Adjustment of interstate migrants by education category } & 2007 & $0.206^{* * *}$ & $(0.053)$ & $0.089^{* * *}$ & $(0.028)$ & $0.117^{* * *}$ & $(0.028)$ \\
\hline & 2000 & $0.200^{* * *}$ & $(0.057)$ & $0.090^{* * *}$ & $(0.030)$ & $0.110^{* * *}$ & $(0.030)$ \\
\hline & 1990 & $0.177^{* * *}$ & $(0.056)$ & $0.057^{*}$ & $(0.031)$ & $0.120^{* * *}$ & $(0.029)$ \\
\hline & 1980 & $0.219^{* *}$ & $(0.091)$ & 0.055 & $(0.040)$ & $0.163^{* * *}$ & $(0.055)$ \\
\hline & 1970 & $0.230^{* * *}$ & $(0.069)$ & 0.041 & $(0.034)$ & $0.189^{* * *}$ & $(0.040)$ \\
\hline \multicolumn{8}{|l|}{ + Adjustment of international migrants: } \\
\hline \multirow[t]{5}{*}{ By education category in country of birth } & 2007 & $0.154^{* * *}$ & $(0.054)$ & 0.038 & $(0.030)$ & $0.117^{* * *}$ & $(0.028)$ \\
\hline & 2000 & $0.160^{* * *}$ & $(0.058)$ & 0.050 & $(0.031)$ & $0.110^{* * *}$ & $(0.030)$ \\
\hline & 1990 & $0.148^{* * *}$ & $(0.057)$ & 0.029 & $(0.032)$ & $0.120^{* * *}$ & (0.029) \\
\hline & 1980 & $0.200^{* *}$ & $(0.089)$ & 0.037 & (0.039) & $0.163^{* * *}$ & $(0.055)$ \\
\hline & 1970 & $0.214^{* * *}$ & $(0.071)$ & 0.025 & $(0.035)$ & $0.189^{* * *}$ & $(0.040)$ \\
\hline \multirow[t]{5}{*}{ By $75^{\text {th }}$ percentile in country of birth } & 2007 & $0.187^{* * *}$ & $(0.051)$ & $0.070^{* *}$ & $(0.027)$ & $0.117^{* * *}$ & $(0.028)$ \\
\hline & 2000 & $0.187^{* * *}$ & $(0.056)$ & $0.077^{* * *}$ & $(0.029)$ & $0.110^{* * *}$ & $(0.030)$ \\
\hline & 1990 & $0.175^{* * *}$ & $(0.055)$ & $0.056^{*}$ & $(0.029)$ & $0.120^{* * *}$ & (0.029) \\
\hline & 1980 & $0.221^{* *}$ & $(0.091)$ & 0.058 & $(0.040)$ & $0.163^{* * *}$ & (0.055) \\
\hline & 1970 & $0.235^{* * *}$ & $(0.070)$ & 0.046 & $(0.034)$ & $0.189^{* * *}$ & $(0.040)$ \\
\hline \multirow[t]{5}{*}{ By $90^{\text {th }}$ percentile in country of birth } & 2007 & $0.229^{* * *}$ & $(0.048)$ & $0.112^{* * *}$ & $(0.025)$ & $0.117^{* * *}$ & $(0.028)$ \\
\hline & 2000 & $0.219^{* * *}$ & $(0.054)$ & $0.109^{* * *}$ & $(0.028)$ & $0.110^{* * *}$ & $(0.030)$ \\
\hline & 1990 & $0.204^{* * *}$ & (0.053) & $0.084^{* * *}$ & $(0.027)$ & $0.120^{* * *}$ & (0.029) \\
\hline & 1980 & $0.241^{* * *}$ & (0.093) & $0.078^{*}$ & (0.041) & $0.163^{* * *}$ & (0.055) \\
\hline & 1970 & $0.252^{* * *}$ & (0.069) & $0.064^{*}$ & (0.033) & $0.189^{* * *}$ & $(0.040)$ \\
\hline
\end{tabular}

Notes: Development accounting results (covariance measure) for 47 U.S. states with different test score specifications. Test scores refer to eighth-grade math. Locals are all persons who report a state of birth equal to the current state of residence. Interstate migrants report another state of birth than state of residence. International migrants report another country of birth than the United States. "By education category" indicates that individuals with/without university education are assigned the test scores of children of parents with/without university education. Calculations assume a return of $w=0.2$ per standard deviation in test scores and a return of $r=0.1$ per year of

schooling. Bootstrapped standard errors in parentheses with 1,000 replications. Significance levels: ${ }^{*} \mathrm{p}<0.10,{ }^{* *} \mathrm{p}<0.05, * * * \mathrm{p}<0.01$. 
Table 4: Development Accounting Results with Projection of Cognitive Skills by Age, 2007

\begin{tabular}{|c|c|c|c|c|c|c|}
\hline \multirow[b]{2}{*}{ Test score specification } & \multicolumn{3}{|c|}{ Covariance Measure } & \multicolumn{3}{|c|}{ Five-State Measure } \\
\hline & $\begin{array}{c}\text { Total } \\
\text { human capital }\end{array}$ & $\begin{array}{c}\text { Test } \\
\text { scores }\end{array}$ & $\begin{array}{l}\text { Years of } \\
\text { schooling }\end{array}$ & $\begin{array}{c}\text { Total } \\
\text { human capital }\end{array}$ & $\begin{array}{c}\text { Test } \\
\text { scores }\end{array}$ & $\begin{array}{l}\text { Years of } \\
\text { schooling }\end{array}$ \\
\hline Baseline: local average adjusted for interstate migrants & $\begin{array}{l}0.184^{* * *} \\
(0.054)\end{array}$ & $\begin{array}{l}0.067^{* *} \\
(0.030)\end{array}$ & $\begin{array}{l}0.117^{* * *} \\
(0.028)\end{array}$ & 0.259 & 0.109 & 0.149 \\
\hline + Adjustment of locals by age category & $\begin{array}{l}0.218^{* * *} \\
(0.064)\end{array}$ & $\begin{array}{l}0.101^{* * *} \\
(0.044)\end{array}$ & $\begin{array}{l}0.117^{* * *} \\
(0.028)\end{array}$ & 0.306 & 0.157 & 0.149 \\
\hline + Adjustment of interstate migrants by age category & $\begin{array}{l}0.236^{* * *} \\
(0.056)\end{array}$ & $\begin{array}{l}0.119^{* * *} \\
(0.036)\end{array}$ & $\begin{array}{l}0.117^{* * *} \\
(0.028)\end{array}$ & 0.327 & 0.177 & 0.149 \\
\hline $\begin{array}{l}+ \text { Adjustment of international migrants } \\
\text { by } 90^{\text {th }} \text { percentile in country of birth }\end{array}$ & $\begin{array}{l}0.258^{* * *} \\
(0.053)\end{array}$ & $\begin{array}{l}0.141^{* * *} \\
(0.035)\end{array}$ & $\begin{array}{l}0.117^{* * *} \\
(0.028)\end{array}$ & 0.352 & 0.203 & 0.149 \\
\hline
\end{tabular}

Notes: Development accounting results for 47 U.S. states with different test score specifications based on projections by age. Test scores refer to eighth-grade math. Locals are all persons who report a state of birth equal to the current state of residence. Interstate migrants report another state of birth than state of residence. International migrants report another country of birth than the United States. Calculations assume a return of $w=0.2$ per standard deviation in test scores and a return of $r=0.1$ per year of schooling. Bootstrapped standard errors in parentheses with 1,000 replications. Significance levels: ${ }^{*} \mathrm{p}<0.10$, ${ }^{* *} \mathrm{p}<0.05$, p $<0.01$. 
Table 5: Development Accounting Results with Projection of Cognitive Skills by Age and Parental Education, 2007

\begin{tabular}{|c|c|c|c|c|c|c|}
\hline \multirow[b]{2}{*}{ Test score specification } & \multicolumn{3}{|c|}{ Covariance Measure } & \multicolumn{3}{|c|}{ Five-State Measure } \\
\hline & $\begin{array}{c}\text { Total } \\
\text { human capital }\end{array}$ & $\begin{array}{c}\text { Test } \\
\text { scores }\end{array}$ & $\begin{array}{l}\text { Years of } \\
\text { schooling }\end{array}$ & $\begin{array}{c}\text { Total } \\
\text { human capital }\end{array}$ & $\begin{array}{c}\text { Test } \\
\text { scores }\end{array}$ & $\begin{array}{l}\text { Years of } \\
\text { schooling }\end{array}$ \\
\hline Baseline: local average adjusted for interstate migrants & $\begin{array}{l}0.184^{* * *} \\
(0.054)\end{array}$ & $\begin{array}{l}0.067^{* *} \\
(0.030)\end{array}$ & $\begin{array}{l}0.117^{* * *} \\
(0.028)\end{array}$ & 0.259 & 0.109 & 0.149 \\
\hline + Adjustment of locals by age-education category & $\begin{array}{c}0.223^{* * *} \\
(0.060)\end{array}$ & $\begin{array}{c}0.106^{* * *} \\
(0.040)\end{array}$ & $\begin{array}{c}0.117^{* * *} \\
(0.028)\end{array}$ & 0.308 & 0.158 & 0.149 \\
\hline $\begin{array}{l}\text { + Adjustment of interstate migrants by age-education } \\
\text { category }\end{array}$ & $\begin{array}{c}0.251^{* * *} \\
(0.056)\end{array}$ & $\begin{array}{c}0.134^{* * *} \\
(0.034)\end{array}$ & $\begin{array}{c}0.117^{* * *} \\
(0.028)\end{array}$ & 0.339 & 0.190 & 0.149 \\
\hline $\begin{array}{l}+ \text { Adjustment of international migrants } \\
\text { by } 90^{\text {th }} \text { percentile in country of birth }\end{array}$ & $\begin{array}{c}0.273^{* * *} \\
(0.053)\end{array}$ & $\begin{array}{l}0.156^{* * *} \\
(0.034)\end{array}$ & $\begin{array}{c}0.117^{* * *} \\
(0.028)\end{array}$ & 0.365 & 0.216 & 0.149 \\
\hline
\end{tabular}

Notes: Development accounting results for 47 U.S. states with different test score specifications based on projections by age and parental education. Test scores refer to eighth-grade math. Locals are all persons who report a state of birth equal to the current state of residence. Interstate migrants report another state of birth than state of residence. International migrants report another country of birth than the United States. "By age-education category" indicates that individuals with/without university education are assigned the (age-specific) test scores of children of parents with/without university education. Calculations assume a return of $w=0.2$ per standard deviation in test scores and a return of $r=0.1$ per year of schooling. Bootstrapped standard errors in parentheses with 1,000 replications. Significance levels: ${ }^{*} \mathrm{p}<0.10,{ }^{* *} \mathrm{p}<0.05,{ }^{* * *} \mathrm{p}<0.01$. 
Table 6: Development Accounting Results with Alternative Projection of Cognitive Skills from SAT Scores by Age, 2007

\begin{tabular}{|c|c|c|c|c|}
\hline & \multicolumn{2}{|c|}{$\begin{array}{l}\text { Linear state trend } \\
\text { before first observed score }\end{array}$} & \multicolumn{2}{|c|}{$\begin{array}{c}\text { Constant } \\
\text { before first observed score }\end{array}$} \\
\hline & $\begin{array}{l}\text { Extrapolation } \\
\text { of NAEP trends }\end{array}$ & $\begin{array}{l}\text { Projection from } \\
\text { state SAT scores }\end{array}$ & $\begin{array}{l}\text { Extrapolation } \\
\text { of NAEP trends }\end{array}$ & $\begin{array}{l}\text { Projection from } \\
\text { state SAT scores }\end{array}$ \\
\hline $\begin{array}{l}\text { Local average adjusted for interstate migrants } \\
\text { by age category }\end{array}$ & $\begin{array}{l}0.119^{* * *} \\
(0.036)\end{array}$ & $\begin{array}{l}0.121^{* *} \\
(0.051)\end{array}$ & $\begin{array}{l}0.109^{* * *} \\
(0.033)\end{array}$ & $\begin{array}{l}0.110^{* *} \\
(0.046)\end{array}$ \\
\hline $\begin{array}{l}+ \text { Adjustment of international migrants } \\
\text { by } 90^{\text {th }} \text { percentile in country of birth }\end{array}$ & $\begin{array}{c}0.141^{* * *} \\
(0.035)\end{array}$ & $\begin{array}{c}0.143^{* * *} \\
(0.051)\end{array}$ & $\begin{array}{c}0.131^{* * *} \\
(0.032)\end{array}$ & $\begin{array}{c}0.133^{* * *} \\
(0.046)\end{array}$ \\
\hline
\end{tabular}

Notes: Development accounting results for 47 U.S. states with different test score specifications based on projections by age. First scores are observed in 1978 in the case of national NAEP and in 1968 in the case of SAT. Test scores refer to eighth-grade math. Interstate migrants report another state of birth than state of residence. International migrants report another country of birth than the United States. Calculations assume a return of $w=0.2$ per standard deviation in test scores and a return of $r=0.1$ per year of schooling. Bootstrapped standard errors in parentheses with 1,000 replications. Significance levels: ${ }^{*} \mathrm{p}<0.10,{ }^{* *} \mathrm{p}<0.05$, $\mathrm{p}<0.01$. 
Table 7: Sensitivity to Alternative Return Parameters

\begin{tabular}{|c|c|c|c|c|c|}
\hline & $r$ & $w$ & $\begin{array}{c}\text { Total } \\
\text { human capital }\end{array}$ & $\begin{array}{l}\text { Test } \\
\text { scores }\end{array}$ & $\begin{array}{c}\text { Years of } \\
\text { schooling }\end{array}$ \\
\hline Baseline & 0.1 & 0.2 & $\begin{array}{c}0.273^{* * *} \\
(0.053)\end{array}$ & $\begin{array}{l}0.156^{* * *} \\
(0.034)\end{array}$ & $\begin{array}{c}0.117^{* * *} \\
(0.028)\end{array}$ \\
\hline \multirow[t]{2}{*}{ Alternative returns to test scores } & 0.1 & 0.15 & $\begin{array}{c}0.234^{* * *} \\
(0.045)\end{array}$ & $\begin{array}{c}0.117^{* * *} \\
(0.025)\end{array}$ & $\begin{array}{c}0.117^{* * *} \\
(0.028)\end{array}$ \\
\hline & 0.1 & 0.25 & $\begin{array}{c}0.312^{* * *} \\
(0.060)\end{array}$ & $\begin{array}{c}0.195^{* * *} \\
(0.042)\end{array}$ & $\begin{array}{c}0.117^{* * *} \\
(0.028)\end{array}$ \\
\hline \multirow[t]{2}{*}{ Alternative returns to years of schooling } & 0.075 & 0.2 & $\begin{array}{l}0.244^{* * *} \\
(0.047)\end{array}$ & $\begin{array}{l}0.156^{* * *} \\
(0.034)\end{array}$ & $\begin{array}{c}0.088^{* * *} \\
(0.021)\end{array}$ \\
\hline & 0.125 & 0.2 & $\begin{array}{c}0.302^{* * *} \\
(0.059)\end{array}$ & $\begin{array}{c}0.156^{* * *} \\
(0.034)\end{array}$ & $\begin{array}{c}0.146^{* * *} \\
(0.035)\end{array}$ \\
\hline \multicolumn{6}{|c|}{ Returns to years of schooling estimated from IPUMS 2007: } \\
\hline Uniform returns estimate & 0.124 & 0.2 & $\begin{array}{c}0.301^{* * *} \\
(0.058)\end{array}$ & $\begin{array}{l}0.156^{* * *} \\
(0.034)\end{array}$ & $\begin{array}{c}0.145^{* * *} \\
(0.035)\end{array}$ \\
\hline Level-specific returns estimates & $\begin{array}{c}r_{\text {non-tertiary }}=0.057 \\
r_{\text {tertiary }}=0.157\end{array}$ & 0.2 & $\begin{array}{c}0.336^{* * *} \\
(0.055)\end{array}$ & $\begin{array}{l}0.156^{* * *} \\
(0.034)\end{array}$ & $\begin{array}{c}0.180^{* * *} \\
(0.032)\end{array}$ \\
\hline
\end{tabular}

Notes: Development accounting results (covariance measure) for 47 U.S. states with different assumptions on the return $w$ per standard deviation in test scores and the return $r$ per year of schooling. Test score specification adjusts locals and interstate migrants by age-education category based on extrapolation of NAEP trends by education category and international migrants by $90^{\text {th }}$ percentile in country of birth. Test scores refer to eighth-grade math. Bootstrapped standard errors in parentheses with 1,000 replications. Significance levels: ${ }^{*} \mathrm{p}<0.10,{ }^{* *} \mathrm{p}<0.05,{ }^{* * *} \mathrm{p}<0.01$. 
Table 8: Growth Accounting Results

\begin{tabular}{|c|c|c|c|c|c|c|c|c|c|}
\hline & \multirow{2}{*}{$\begin{array}{l}\text { Average annual } \\
\text { growth rate of } \\
\text { real GDP per } \\
\text { capita (percent) }\end{array}$} & \multirow{2}{*}{$\begin{array}{c}\text { Absolute } \\
\text { change in } \\
\text { years of } \\
\text { schooling }\end{array}$} & \multirow{2}{*}{$\begin{array}{c}\text { Estimated } \\
\text { annual change } \\
\text { in test scores }\end{array}$} & \multicolumn{3}{|c|}{$\begin{array}{l}\text { Average annual growth rate } \\
\text { accounted for by }\end{array}$} & \multicolumn{3}{|c|}{ Percent of total growth } \\
\hline & & & & $\begin{array}{c}\text { Total } \\
\text { human capital }\end{array}$ & $\begin{array}{c}\text { Test } \\
\text { scores }\end{array}$ & $\begin{array}{c}\text { Years of } \\
\text { schooling }\end{array}$ & $\begin{array}{c}\text { Total } \\
\text { human capital }\end{array}$ & $\begin{array}{c}\text { Test } \\
\text { scores }\end{array}$ & $\begin{array}{l}\text { Years of } \\
\text { schooling }\end{array}$ \\
\hline $1970-1980$ & 2.17 & 0.89 & 2.6 & 0.94 & 0.35 & 0.59 & 43.1 & 15.9 & 27.2 \\
\hline 1980-1990 & 2.39 & 0.56 & 2.6 & 0.72 & 0.35 & 0.37 & 30.1 & 14.5 & 15.6 \\
\hline $1990-2000$ & 2.47 & 0.29 & 2.6 & 0.54 & 0.35 & 0.19 & 21.8 & 14.0 & 7.8 \\
\hline 2000-2007 & 1.52 & 0.22 & 2.6 & 0.55 & 0.35 & 0.20 & 36.3 & 22.8 & 13.5 \\
\hline $1970-2007$ & 2.19 & 1.95 & 2.6 & 0.70 & 0.35 & 0.35 & 31.9 & 15.8 & 16.1 \\
\hline $1970-2000$ & 2.35 & 1.74 & 2.6 & 0.73 & 0.35 & 0.39 & 31.2 & 14.8 & 16.5 \\
\hline 1970-1990 & 2.28 & 1.45 & 2.6 & 0.83 & 0.35 & 0.48 & 36.3 & 15.2 & 21.1 \\
\hline 1990-2007 & 2.08 & 0.50 & 2.6 & 0.54 & 0.35 & 0.20 & 26.2 & 16.7 & 9.5 \\
\hline
\end{tabular}

Notes: Estimated annual change in test scores: in percent of a standard deviation, obtained from a regression of available NAEP test scores on years for each state, 1992-2011. 
Figure A1: Cognitive Skills and Years of Schooling across U.S. States, 2007

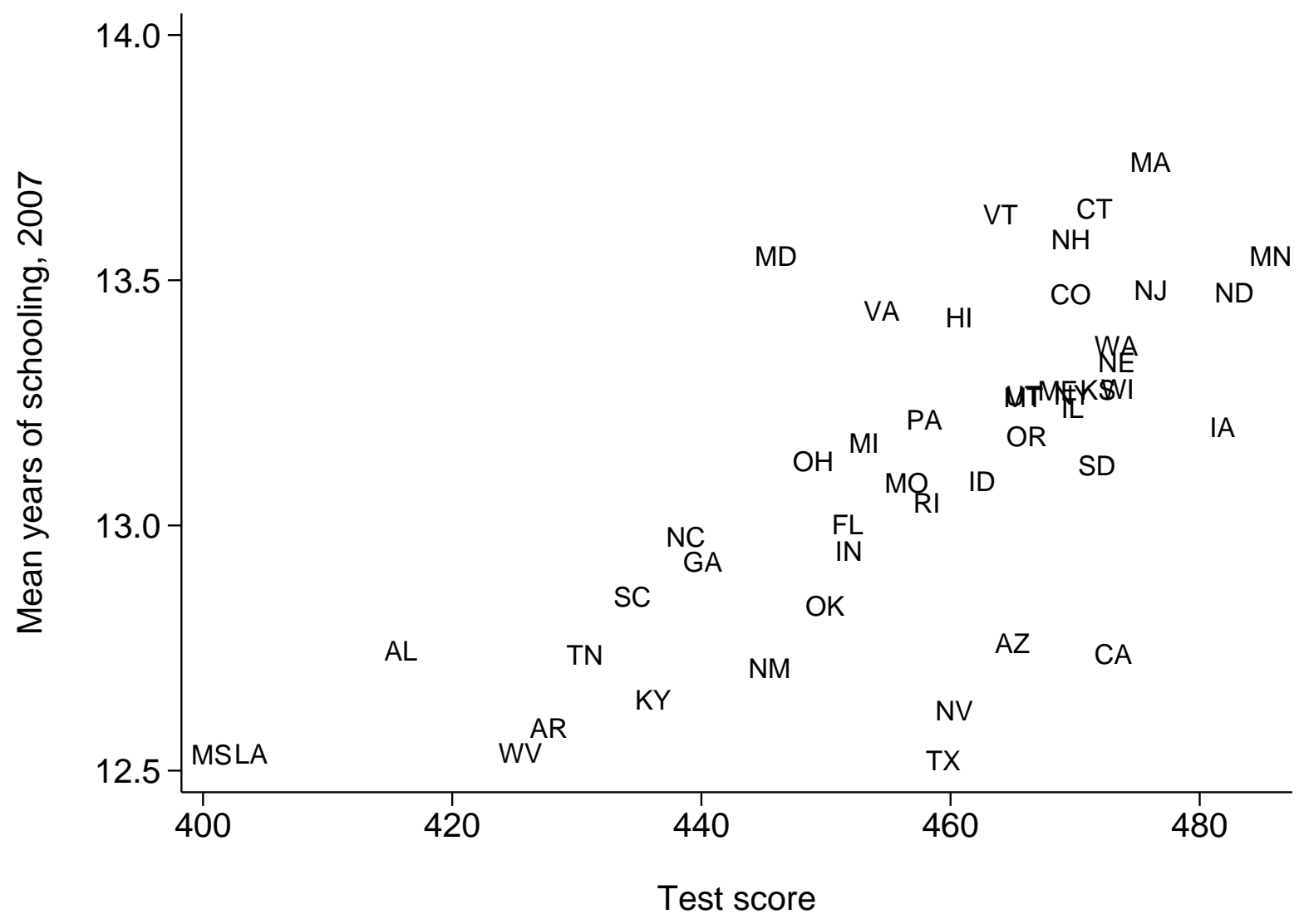

Notes: Scatterplot of cognitive skill measure (adjusted for selective interstate and for international migration by the $90^{\text {th }}$ percentile) and average years of schooling of the working-age population across U.S. states, 2007. Source:

Authors' calculations based on data from Ruggles et al. (2010) and National Center for Education Statistics (2014). 
Table A1: Summary Statistics

\begin{tabular}{|c|c|c|c|c|c|}
\hline & Obs. & Mean & Std. dev. & Min. & Max. \\
\hline Real GDP per capita, 2007 & 47 & 41,218 & 6,388 & 29,302 & 59,251 \\
\hline Years of schooling, 2007 & 47 & 13.11 & 0.35 & 12.52 & 13.74 \\
\hline \multicolumn{6}{|l|}{ Test scores: } \\
\hline Baseline: local average adjusted for interstate migrants & 47 & 499.9 & 15.98 & 460.4 & 527.7 \\
\hline + Adjustment of locals by education category & 47 & 494.4 & 15.46 & 454.9 & 521.3 \\
\hline + Adjustment of interstate migrants by education category & 47 & 493.9 & 15.80 & 453.1 & 522.0 \\
\hline \multicolumn{6}{|l|}{ + Adjustment of international migrants } \\
\hline By education category in country of birth & 47 & 487.4 & 15.69 & 452.5 & 518.0 \\
\hline By $75^{\text {th }}$ percentile in country of birth & 47 & 492.3 & 14.86 & 453.8 & 519.0 \\
\hline By $90^{\text {th }}$ percentile in country of birth & 47 & 498.4 & 15.21 & 455.2 & 522.9 \\
\hline Age adjustment with extrapolation of NAEP trends by education category & 47 & 443.2 & 22.04 & 382.3 & 477.0 \\
\hline Age adjustment with projection from SAT scores & 47 & 407.9 & 27.76 & 321.9 & 456.6 \\
\hline Growth rate of real GDP per capita, 1970-2007 & 47 & 2.24 & 0.31 & 1.56 & 2.89 \\
\hline Change in years of schooling, 1970-2007 & 47 & 2.02 & 0.45 & 0.78 & 2.86 \\
\hline Estimated annual change in test scores, 1992-2011 & 47 & 2.61 & 0.93 & 0.39 & 4.52 \\
\hline
\end{tabular}

Notes: See sections 2.2, 2.3, and 3.1 for details on the data. Test scores refer to eighth-grade math. Locals are all persons who report a state of birth equal to the current state of residence. Interstate migrants report another state of birth than state of residence. International migrants report another country of birth than the United States. "By education category" indicates that individuals with/without university education are assigned the test scores of children of parents with/without university education. 
Table A2: Main Data by State

\begin{tabular}{|c|c|c|c|c|c|c|c|}
\hline & \multirow[b]{2}{*}{$\begin{array}{c}\text { Real GDP per } \\
\text { capita } 2007 \\
\text { (1) }\end{array}$} & \multirow[b]{2}{*}{$\begin{array}{c}\text { Years of } \\
\text { schooling } 2007 \\
\text { (2) }\end{array}$} & \multicolumn{5}{|c|}{ Test scores } \\
\hline & & & $\begin{array}{c}\text { Average } \\
\text { NAEP score } \\
(3)\end{array}$ & $\begin{array}{l}\text { Baseline } \\
\text { score } \\
(4)\end{array}$ & $\begin{array}{c}\text { Adjusted for } \\
\text { selective migration } \\
\text { (5) }\end{array}$ & $\begin{array}{c}\text { Projection by } \\
\text { NAEP trends } \\
(6)\end{array}$ & $\begin{array}{c}\text { Projection from } \\
\text { SAT scores } \\
(7)\end{array}$ \\
\hline Alabama & 33,506 & 12.74 & 461.1 & 469.0 & 464.6 & 400.6 & 373.2 \\
\hline Alaska & 61,877 & 13.15 & 504.8 & 501.9 & 505.1 & 452.2 & 413.2 \\
\hline Arizona & 39,712 & 12.76 & 487.7 & 493.5 & 501.1 & 453.6 & 422.7 \\
\hline Arkansas & 32,338 & 12.59 & 475.0 & 481.8 & 477.4 & 411.4 & 387.2 \\
\hline California & 48,777 & 12.74 & 472.3 & 478.5 & 503.0 & 464.4 & 439.7 \\
\hline Colorado & 47,735 & 13.47 & 513.6 & 506.4 & 508.5 & 457.3 & 419.3 \\
\hline Connecticut & 59,251 & 13.65 & 515.0 & 511.5 & 508.6 & 459.5 & 423.9 \\
\hline Delaware & 64,604 & 13.15 & 497.2 & 499.9 & 497.7 & 430.4 & 389.9 \\
\hline Florida & 39,153 & 13.00 & 483.5 & 491.5 & 491.2 & 438.2 & 403.7 \\
\hline Georgia & 40,389 & 12.93 & 481.5 & 485.6 & 485.1 & 426.1 & 397.0 \\
\hline Hawaii & 46,022 & 13.42 & 470.8 & 478.2 & 497.2 & 449.2 & 411.9 \\
\hline Idaho & 34,079 & 13.09 & 512.2 & 504.8 & 501.9 & 450.6 & 421.5 \\
\hline Illinois & 46,646 & 13.24 & 498.6 & 498.7 & 504.3 & 459.2 & 419.0 \\
\hline Indiana & 38,777 & 12.95 & 511.0 & 506.8 & 499.7 & 437.0 & 404.5 \\
\hline Iowa & 42,242 & 13.20 & 521.7 & 517.5 & 510.9 & 477.0 & 456.6 \\
\hline Kansas & 40,943 & 13.28 & 520.2 & 512.2 & 509.2 & 460.5 & 422.4 \\
\hline Kentucky & 33,412 & 12.64 & 489.2 & 492.1 & 484.8 & 420.8 & 381.2 \\
\hline Louisiana & 44,778 & 12.53 & 462.9 & 467.7 & 463.0 & 382.9 & 345.3 \\
\hline Maine & 34,944 & 13.27 & 518.9 & 516.0 & 508.3 & 456.4 & 429.4 \\
\hline Maryland & 45,469 & 13.55 & 501.9 & 492.4 & 491.7 & 429.3 & 392.2 \\
\hline Massachusetts & 51,781 & 13.74 & 530.5 & 524.0 & 522.6 & 458.2 & 397.1 \\
\hline Michigan & 36,532 & 13.17 & 499.0 & 498.6 & 494.0 & 441.6 & 410.8 \\
\hline Minnesota & 45,987 & 13.55 & 534.8 & 527.7 & 522.9 & 474.8 & 438.4 \\
\hline Mississippi & 29,727 & 12.53 & 450.8 & 460.4 & 455.2 & 382.3 & 321.9 \\
\hline Missouri & 37,395 & 13.09 & 501.6 & 500.6 & 495.8 & 445.0 & 412.1 \\
\hline Montana & 34,372 & 13.26 & 528.5 & 516.5 & 509.5 & 452.1 & 434.7 \\
\hline Nebraska & 43,525 & 13.33 & 517.1 & 513.8 & 509.2 & 464.6 & 446.6 \\
\hline Nevada & 48,392 & 12.62 & 477.2 & 486.9 & 496.2 & 449.3 & 422.0 \\
\hline New Hampshire & 41,668 & 13.58 & 524.0 & 520.0 & 515.1 & 453.8 & 403.9 \\
\hline
\end{tabular}

(continued on next page) 
Table A2 (continued)

\begin{tabular}{|c|c|c|c|c|c|c|c|}
\hline & \multirow[b]{2}{*}{$\begin{array}{c}\text { Real GDP per } \\
\text { capita } 2007 \\
\text { (1) }\end{array}$} & \multirow[b]{2}{*}{$\begin{array}{c}\text { Years of } \\
\text { schooling } 2007 \\
(2)\end{array}$} & \multicolumn{5}{|c|}{ Test scores } \\
\hline & & & $\begin{array}{c}\text { Average } \\
\text { NAEP score } \\
(3)\end{array}$ & $\begin{array}{c}\text { Baseline } \\
\text { score } \\
(4)\end{array}$ & $\begin{array}{c}\text { Adjusted for } \\
\text { selective migration } \\
\text { (5) }\end{array}$ & $\begin{array}{l}\text { Projection by } \\
\text { NAEP trends } \\
(6)\end{array}$ & $\begin{array}{c}\text { Projection from } \\
\text { SAT scores } \\
(7)\end{array}$ \\
\hline New Jersey & 51,337 & 13.48 & 519.0 & 513.9 & 514.1 & 463.1 & 430.8 \\
\hline New Mexico & 35,313 & 12.71 & 468.2 & 480.9 & 484.8 & 433.3 & 408.1 \\
\hline New York & 53,165 & 13.27 & 497.8 & 498.4 & 506.4 & 457.8 & 424.0 \\
\hline North Carolina & 41,123 & 12.98 & 497.3 & 497.1 & 493.9 & 417.7 & 359.9 \\
\hline North Dakota & 41,329 & 13.47 & 531.8 & 527.0 & 520.1 & 472.7 & 456.5 \\
\hline Ohio & 38,389 & 13.13 & 510.2 & 506.8 & 500.1 & 431.9 & 393.8 \\
\hline Oklahoma & 36,504 & 12.84 & 488.5 & 491.4 & 487.6 & 439.2 & 413.8 \\
\hline Oregon & 42,422 & 13.18 & 511.0 & 503.1 & 506.2 & 453.0 & 422.4 \\
\hline Pennsylvania & 39,951 & 13.21 & 509.2 & 507.7 & 501.0 & 443.8 & 406.3 \\
\hline Rhode Island & 42,274 & 13.05 & 489.4 & 495.8 & 496.1 & 446.0 & 411.6 \\
\hline South Carolina & 33,539 & 12.85 & 490.5 & 492.7 & 487.5 & 415.5 & 355.2 \\
\hline South Dakota & 41,649 & 13.12 & 521.6 & 518.6 & 508.9 & 460.8 & 427.3 \\
\hline Tennessee & 37,068 & 12.74 & 475.8 & 482.1 & 477.6 & 415.8 & 374.7 \\
\hline Texas & 45,502 & 12.52 & 502.7 & 499.8 & 503.6 & 444.9 & 407.0 \\
\hline Utah & 39,464 & 13.26 & 506.5 & 502.9 & 499.8 & 457.3 & 437.3 \\
\hline Vermont & 36,445 & 13.63 & 525.2 & 517.1 & 511.3 & 447.1 & 399.7 \\
\hline Virginia & 47,501 & 13.44 & 508.3 & 501.8 & 499.5 & 438.9 & 400.5 \\
\hline Washington & 47,553 & 13.37 & 513.8 & 506.8 & 514.0 & 459.9 & 391.2 \\
\hline West Virginia & 29,302 & 12.53 & 475.7 & 483.0 & 472.6 & 411.7 & 380.0 \\
\hline Wisconsin & 39,841 & 13.28 & 521.1 & 516.5 & 510.2 & 463.9 & 434.1 \\
\hline Wyoming & 59,558 & 13.22 & 514.1 & 509.4 & 505.9 & 453.2 & 424.6 \\
\hline
\end{tabular}

Notes: (1) Real GDP per capita in 2005 U.S. dollars. (2) Mean years of completed schooling, 2007. (3) Estimated average $8^{\text {th }}$-grade math NAEP score from 1992 to 2011, obtained from a regression of NAEP test scores on time and state fixed effects; see Appendix B.1. (4) Baseline: local average adjusted for interstate migrants by average test score of their state of birth. (5) Baseline + adjustment of locals by education category + adjustment of interstate migrants by education category + adjustment of international migrants by $90^{\text {th }}$ percentile in country of birth. (6) Age adjustment with extrapolation of NAEP trends by education category; see Appendix B.4. (7) Age adjustment with projection from SAT scores; see Appendix B.4. 
Table A3: Main Source Countries

\begin{tabular}{|c|c|c|c|}
\hline Country of Birth & $\begin{array}{c}\text { Total Census Obser- } \\
\text { vations, } 1940-2010\end{array}$ & $\begin{array}{l}\text { Share of all immigrants } \\
\text { (in percent) }\end{array}$ & Imputation of international test scores \\
\hline Mexico & $1,054,264$ & 24.14 & \\
\hline Philippines & 192,335 & 4.40 & \\
\hline Puerto Rico & 184,529 & 4.22 & NAEP \\
\hline Germany & 138,950 & 3.18 & \\
\hline India & 136,515 & 3.13 & Southeast Asia: Indonesia, Malaysia, Philippines, Singapore, Thailand + Iran \\
\hline Canada & 136,424 & 3.12 & \\
\hline Cuba & 115,914 & 2.65 & Central America: El Salvador, Panama, Honduras, Trinidad\&Tobago \\
\hline China & 115,670 & 2.65 & East Asia: Shanghai-China, Hong Kong, Macao-China, Mongolia, Taiwan (Chinese Taipei), Japan, Korea, Rep. \\
\hline Vietnam & 111,037 & 2.54 & Southeast Asia: Indonesia, Malaysia, Philippines, Singapore, Thailand \\
\hline Italy & 102,190 & 2.34 & \\
\hline El Salvador & 93,766 & 2.15 & \\
\hline Korea & 87,184 & 2.00 & South Korea \\
\hline England & 81,712 & 1.87 & \\
\hline USA, Unknown State & 72,212 & 1.65 & NAEP \\
\hline Poland & 71,464 & 1.64 & \\
\hline Dominican Republic & 67,583 & 1.55 & Central America \\
\hline Japan & 62,327 & 1.43 & \\
\hline Jamaica & 58,633 & 1.34 & Central America \\
\hline Colombia & 57,598 & 1.32 & \\
\hline Guatemala & 55,451 & 1.27 & Central America \\
\hline Abroad, ns & 52,545 & 1.20 & Total Average \\
\hline Other USSR/Russia & 44,915 & 1.03 & USSR: Russia, Moldova, Ukraine, Armenia, Azerbaijan, Georgia, Kazakhstan, Kyrgyzstan \\
\hline Taiwan & 40,817 & 0.93 & \\
\hline Haiti & 40,287 & 0.92 & Central America \\
\hline West Germany & 36,231 & 0.83 & Germany \\
\hline Iran & 34,117 & 0.78 & \\
\hline Ecuador & 32,475 & 0.74 & South America: Argentina, Brazil, Chile, Colombia, Peru, Uruguay \\
\hline Peru & 32,047 & 0.73 & \\
\hline Portugal & 31,728 & 0.73 & \\
\hline Honduras & 31,141 & 0.71 & \\
\hline Ireland & 30,295 & 0.69 & \\
\hline Greece & 29,979 & 0.69 & \\
\hline France & 28,703 & 0.66 & \\
\hline Brazil & 25,754 & 0.59 & \\
\hline United Kingdom & 25,565 & 0.59 & \\
\hline Hong Kong & 25,324 & 0.58 & \\
\hline Nicaragua & 23,920 & 0.55 & Central America \\
\hline Pakistan & 23,123 & 0.53 & Southeast Asia + Iran \\
\hline Guyana/British Guiana & 22,425 & 0.51 & South America \\
\hline Laos & 21,998 & 0.50 & Southeast Asia \\
\hline Trinidad and Tobago & 21,731 & 0.50 & \\
\hline
\end{tabular}

Notes: Main source countries/regions of immigrants living in the United States. Only countries with a share of the total immigrant inflow of at least 0.5 percent. Averages over all available Census years. Imputation: Countries/ region by which test scores are imputed in cases without international test score data. Source: Authors' calculations based on Ruggles et al. (2010). 
Table A4: Five-State Measure: Alternative Numbers of Top and Bottom States

\begin{tabular}{lcc}
\hline \hline & Total human capital & Test scores \\
Five-state measure & 0.365 & 0.216 \\
Three-state measure & 0.364 & 0.149 \\
Seven-state measure & 0.171 & 0.193 \\
\hline \hline
\end{tabular}

Notes: Development accounting results (five-state measure) for 47 U.S. states with different numbers of countries used at the top and bottom of the state distribution. Test score specification adjusts locals and interstate migrants by age-education category based on extrapolation of NAEP trends by education category and international migrants by $90^{\text {th }}$ percentile in country of birth. Test scores refer to eighth-grade math. Calculations assume a return of $w=0.2$ per standard deviation in test scores and a return of $r=0.1$ per year of schooling. 
Table A5: Growth Accounting by State, 1970-2007

\begin{tabular}{|c|c|c|c|c|c|c|c|c|c|}
\hline & \multirow{2}{*}{$\begin{array}{l}\text { Average annual } \\
\text { growth rate of } \\
\text { real GDP per } \\
\text { capita (percent) }\end{array}$} & \multirow{2}{*}{$\begin{array}{l}\text { Absolute } \\
\text { change in } \\
\text { years of } \\
\text { schooling }\end{array}$} & \multirow{2}{*}{$\begin{array}{c}\text { Estimated } \\
\text { annual change } \\
\text { in test scores }\end{array}$} & \multicolumn{3}{|c|}{$\begin{array}{l}\text { Average annual growth rate } \\
\text { accounted for by }\end{array}$} & \multicolumn{3}{|c|}{ Percent of total growth } \\
\hline & & & & $\begin{array}{c}\text { Total } \\
\text { human capital }\end{array}$ & $\begin{array}{c}\text { Test } \\
\text { scores }\end{array}$ & $\begin{array}{c}\text { Years of } \\
\text { schooling }\end{array}$ & $\begin{array}{c}\text { Total } \\
\text { human capital }\end{array}$ & $\begin{array}{c}\text { Test } \\
\text { scores }\end{array}$ & $\begin{array}{l}\text { Years of } \\
\text { schooling }\end{array}$ \\
\hline & $(1)$ & $(2)$ & (3) & (4) & (5) & (6) & $(7)$ & $(8)$ & (9) \\
\hline Alabama & 2.35 & 2.65 & 2.68 & 0.83 & 0.36 & 0.48 & 35.5 & 15.2 & 20.3 \\
\hline Arizona & 2.03 & 1.60 & 2.30 & 0.60 & 0.31 & 0.29 & 29.3 & 15.1 & 14.2 \\
\hline Arkansas & 2.39 & 2.50 & 3.75 & 0.95 & 0.50 & 0.45 & 39.7 & 20.9 & 18.8 \\
\hline California & 2.14 & 1.01 & 2.16 & 0.47 & 0.29 & 0.18 & 21.9 & 13.4 & 8.5 \\
\hline Colorado & 2.58 & 1.57 & 2.87 & 0.67 & 0.38 & 0.28 & 25.8 & 14.8 & 10.9 \\
\hline Connecticut & 2.79 & 2.25 & 1.99 & 0.67 & 0.27 & 0.41 & 24.1 & 9.5 & 14.5 \\
\hline Florida & 2.16 & 1.98 & 3.26 & 0.79 & 0.43 & 0.36 & 36.6 & 20.1 & 16.5 \\
\hline Georgia & 2.44 & 2.66 & 3.26 & 0.91 & 0.43 & 0.48 & 37.5 & 17.8 & 19.7 \\
\hline Hawaii & 1.63 & 1.96 & 2.94 & 0.75 & 0.39 & 0.35 & 45.8 & 24.1 & 21.7 \\
\hline Idaho & 2.02 & 1.53 & 2.07 & 0.55 & 0.28 & 0.28 & 27.3 & 13.6 & 13.7 \\
\hline Illinois & 2.03 & 2.03 & 2.28 & 0.67 & 0.3 & 0.37 & 32.9 & 15.0 & 18.0 \\
\hline Indiana & 2.01 & 1.85 & 2.48 & 0.66 & 0.33 & 0.33 & 33.0 & 16.4 & 16.6 \\
\hline Iowa & 2.32 & 1.64 & 0.39 & 0.35 & 0.05 & 0.30 & 15.0 & 2.3 & 12.8 \\
\hline Kansas & 2.43 & 1.63 & 1.91 & 0.55 & 0.25 & 0.29 & 22.5 & 10.5 & 12.1 \\
\hline Kentucky & 1.86 & 2.62 & 3.10 & 0.88 & 0.41 & 0.47 & 47.7 & 22.2 & 25.4 \\
\hline Louisiana & 2.41 & 2.33 & 4.17 & 0.98 & 0.56 & 0.42 & 40.6 & 23.1 & 17.5 \\
\hline Maine & 2.20 & 2.20 & 1.33 & 0.57 & 0.18 & 0.40 & 26.0 & 8.1 & 18.0 \\
\hline Maryland & 2.41 & 2.32 & 3.91 & 0.94 & 0.52 & 0.42 & 39.1 & 21.7 & 17.4 \\
\hline Massachusetts & 2.56 & 2.21 & 4.52 & 1.00 & 0.60 & 0.40 & 39.1 & 23.5 & 15.6 \\
\hline Michigan & 1.56 & 1.97 & 1.53 & 0.56 & 0.20 & 0.36 & 35.8 & 13.1 & 22.8 \\
\hline Minnesota & 2.37 & 1.96 & 2.11 & 0.63 & 0.28 & 0.35 & 26.7 & 11.9 & 14.9 \\
\hline Mississippi & 2.36 & 2.46 & 3.71 & 0.94 & 0.50 & 0.44 & 39.7 & 21.0 & 18.7 \\
\hline Missouri & 1.89 & 2.10 & 2.23 & 0.68 & 0.30 & 0.38 & 35.7 & 15.7 & 20.0 \\
\hline Montana & 2.10 & 1.68 & 1.90 & 0.55 & 0.25 & 0.30 & 26.4 & 12.0 & 14.4 \\
\hline Nebraska & 2.42 & 1.67 & 0.97 & 0.43 & 0.13 & 0.30 & 17.8 & 5.3 & 12.4 \\
\hline Nevada & 1.69 & 0.78 & 3.11 & 0.56 & 0.42 & 0.14 & 32.9 & 24.6 & 8.3 \\
\hline New Hampshire & 2.56 & 2.16 & 2.25 & 0.69 & 0.30 & 0.39 & 26.9 & 11.7 & 15.2 \\
\hline New Jersey & 2.41 & 2.25 & 3.52 & 0.88 & 0.47 & 0.41 & 36.3 & 19.5 & 16.8 \\
\hline
\end{tabular}

(continued on next page) 
Table A5 (continued)

\begin{tabular}{|c|c|c|c|c|c|c|c|c|c|}
\hline & \multirow{2}{*}{$\begin{array}{l}\text { Average annual } \\
\text { growth rate of } \\
\text { real GDP per } \\
\text { capita (percent) }\end{array}$} & \multirow{2}{*}{$\begin{array}{c}\text { Absolute } \\
\text { change in } \\
\text { years of } \\
\text { schooling }\end{array}$} & \multirow{2}{*}{$\begin{array}{c}\text { Estimated } \\
\text { annual change } \\
\text { in test scores }\end{array}$} & \multicolumn{3}{|c|}{$\begin{array}{l}\text { Average annual growth rate } \\
\text { accounted for by }\end{array}$} & \multicolumn{3}{|c|}{ Percent of total growth } \\
\hline & & & & $\begin{array}{c}\text { Total } \\
\text { human capital } \\
(4)\end{array}$ & $\begin{array}{c}\text { Test } \\
\text { scores } \\
(5) \\
\end{array}$ & $\begin{array}{c}\text { Years of } \\
\text { schooling } \\
(6) \\
\end{array}$ & $\begin{array}{c}\text { Total } \\
\text { human capital } \\
(7) \\
\end{array}$ & $\begin{array}{c}\text { Test } \\
\text { scores } \\
(8) \\
\end{array}$ & $\begin{array}{c}\text { Years of } \\
\text { schooling } \\
(9) \\
\end{array}$ \\
\hline New Mexico & 2.01 & 1.71 & 2.22 & 0.60 & 0.30 & 0.31 & 30.1 & 14.8 & 15.3 \\
\hline New York & 2.12 & 2.05 & 2.66 & 0.72 & 0.35 & 0.37 & 34.1 & 16.7 & 17.4 \\
\hline North Carolina & 2.30 & 2.76 & 4.24 & 1.06 & 0.57 & 0.50 & 46.2 & 24.6 & 21.7 \\
\hline North Dakota & 2.86 & 2.38 & 1.76 & 0.66 & 0.24 & 0.43 & 23.2 & 8.2 & 15.0 \\
\hline Ohio & 1.80 & 1.92 & 2.99 & 0.74 & 0.40 & 0.35 & 41.4 & 22.2 & 19.2 \\
\hline Oklahoma & 2.26 & 1.71 & 1.71 & 0.54 & 0.23 & 0.31 & 23.7 & 10.1 & 13.7 \\
\hline Oregon & 2.31 & 1.58 & 1.54 & 0.49 & 0.21 & 0.28 & 21.2 & 8.9 & 12.3 \\
\hline Pennsylvania & 2.04 & 2.20 & 2.69 & 0.76 & 0.36 & 0.40 & 37.0 & 17.6 & 19.4 \\
\hline Rhode Island & 2.32 & 2.19 & 2.45 & 0.72 & 0.33 & 0.39 & 31.1 & 14.1 & 17.0 \\
\hline South Carolina & 2.30 & 2.86 & 4.04 & 1.05 & 0.54 & 0.51 & 45.8 & 23.4 & 22.4 \\
\hline South Dakota & 2.89 & 1.89 & 2.04 & 0.61 & 0.27 & 0.34 & 21.2 & 9.4 & 11.8 \\
\hline Tennessee & 2.29 & 2.52 & 2.82 & 0.83 & 0.38 & 0.45 & 36.3 & 16.4 & 19.9 \\
\hline Texas & 2.48 & 1.85 & 4.01 & 0.87 & 0.54 & 0.33 & 34.9 & 21.6 & 13.4 \\
\hline Utah & 2.41 & 1.22 & 1.68 & 0.44 & 0.22 & 0.22 & 18.4 & 9.3 & 9.1 \\
\hline Vermont & 2.00 & 2.19 & 3.20 & 0.82 & 0.43 & 0.39 & 41.0 & 21.3 & 19.7 \\
\hline Virginia & 2.69 & 2.66 & 3.69 & 0.97 & 0.49 & 0.48 & 36.1 & 18.3 & 17.9 \\
\hline Washington & 2.24 & 1.48 & 2.64 & 0.62 & 0.35 & 0.27 & 27.6 & 15.7 & 11.9 \\
\hline West Virginia & 1.67 & 2.33 & 2.07 & 0.70 & 0.28 & 0.42 & 41.6 & 16.5 & 25.1 \\
\hline Wisconsin & 2.17 & 1.94 & 1.60 & 0.56 & 0.21 & 0.35 & 26.0 & 9.8 & 16.2 \\
\hline
\end{tabular}

Notes: Estimated annual change in test scores: in percent of a standard deviation, obtained from a regression of available NAEP test scores on years for each state, 1992-2011. 